\title{
Sex and Geographic Differences in Health of the Early Inhabitants of the Mariana Islands
}

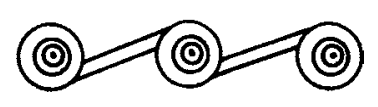

\author{
MICHAEL PIETRUSEWSKY, MICHELE TOOMAY DOUGLAS, MARILYN \\ K. SWIFT, RANDY A. HARPER, AND MICHAEL A. FLEMING
}

\section{INTRODUCTION}

Previous investigations of Health in the Mariana Islands indicated that the prehistoric inhabitants living on the smaller islands of the southern group of islands in this archipelago (i.e., Rota, Tinian, and Saipan) were less healthy than those living on Guam, the largest island (Pietrusewsky et al. 1997; Pietrusewsky et al. 2010, 2011, 2014). These islands' greater susceptibility to environmental perturbations, smaller landmass, remoteness, lower rainfall, access to fresh water, narrow and noncontinuous fringing reefs, and sea level fluctuations have been cited as possible reasons for the observed differences (Hunter-Anderson 2010). This study expands on previous research by examining intra-island differences in health between males and females and whether or not these sex differences are consistent across the islands. We also address whether there are differences in male and female health between the islands. In addition to physical environmental factors, cultural and biological factors that may explain these differences are discussed.

Sex differences in skeletal stress indicators have attracted the attention of investigators since early theories of the effects of population growth and subsistence transitions on human populations were proposed (Cohen and Armelagos 1984). Larsen (2015) related a nearly universal greater caries rate in females to differing food consumption, and noted a gradually accumulating body of global literature identifying sex differences in antemortem tooth loss (AMTL), nonspecific infections, trauma, osteoarthritis, and cross-sectional bone geometry, all leading to an expanded and more nuanced understanding of human lifeways. Although some sex differences are intuitively expected based on physical differences and by extension activity differences (e.g., greater fracture rates in males), others are not. Interpretation requires careful examination of the specific cultural and physical environment.

Michael Pietrusewsky is Professor Emeritus at the Department of Anthropology, University of Hawai' $i$ at Mānoa. Michele Toomay Douglas is affiliate graduate faculty at the Department of Anthropology, University of Hawai'i at Mānoa. Marilyn K. Swift is an archaeologist at Swift and Harper Archaeological Resource Consulting in Saipan. Randy A. Harper is an archaeologist at Swift and Harper Archaeological Resource Consulting in Saipan. Michael A. Fleming is an archaeologist at Swift and Harper Archaeological Resource Consulting in Saipan. 
Research has shown that physiological differences in hormone levels and immune function in males and females may contribute to observed differences in stress indicators. For example, iron deficiency anemia is more common and more severe in boys (Stuart-Macadam 1998); females have a greater ability to resist nutritional deficiencies and have greater immune reactivity and better immune response than males except during pregnancy, when the immune function is suppressed (Ortner 1998). Given equal nutritional stress, male stature will be impacted more than female stature because of the buffering effects of female hormones, unless there is differential access to foods that discriminates against females (Stini 1985). Lukacs and Largaespada (2006:540) argue that "physiological changes associated with fluctuating hormone levels during individual life histories" of women are likely to have a greater influence on caries rates than earlier dental eruption and differential access to foods. These findings suggest that sex differences in indicators of stress in skeletal series are multifactorial and not easily attributed to behavioral or cultural differences.

\section{THE MARIANA ISLANDS}

The Mariana Islands, made up of the summits of 15 volcanic islands and numerous smaller geologic outcroppings, are located between $13^{\circ}$ and $21^{\circ} \mathrm{N}$ latitude and $144^{\circ}$ and $146^{\circ}$ E longitude in the western Pacific (Fig. 1). Guam, Rota, Tinian, and Saipan, the largest islands in the archipelago, are the most favorable to human settlement in prehistory and in modern times. Geologically, the southern islands are a combination of volcanic and raised coralline deposits surrounded by a fringing reef. The remaining, generally unpopulated, northern islands are of more recent volcanic origin.

Guam, the largest island in the Mariana Islands and Micronesia, measures approximately $549 \mathrm{~km}^{2}$. The island is divided into a volcanic southern section of mountainous grasslands and a northern uplifted limestone plateau surrounded by cliffs. Prior to the arrival of the first humans, approximately 3500 B.P., the northern half of the island was heavily forested. The fringing reefs, lagoons, and bays found on the west side of the island (e.g., Tumon Bay and Agana Bay) are among the most densely settled areas of the island in ancient and modern times. Fresh water is found year-round in rivers, streams, and small mountain pools on Guam.

Rota, located $76 \mathrm{~km}$ north of Guam, is only $85.4 \mathrm{~km}^{2}$ in area and the smallest of the four major southern islands. The island consists of a series of limestone terraces surrounding a volcanic core, with a narrow fringing reef, few or no lagoons, and little surface water. Rainfall is concentrated during the wet season, making Rota very vulnerable to water shortages during the dry season (Butler 1988:11). However, water caves, found throughout the island, undoubtedly were, and continue to be, a valuable source of fresh water on Rota (Keel et al. 2005).

Tinian, located $117 \mathrm{~km}$ north of Rota, is the third largest island, with a land area of $101 \mathrm{~km}^{2}$. Tinian Island is essentially a terraced platform of elevated reef limestone of varied topography (Fosberg 1960). Hagoi Lake on the north end of the island is the only permanent surface water found on the island (Fosberg 1960).

Saipan, located approximately $8 \mathrm{~km}$ north of Tinian, is approximately $120.6 \mathrm{~km}^{2}$ in area, composed of a volcanic core overlain with younger uplifted limestone plateaus of varying elevations and steep escarpments (Carruth 2003). The western coast of Saipan is flanked by a large lagoon and fringing reefs, an extensive swamp, and Lake Susupe, a large brackish lake (Young 1989). A freshwater lens in saturated limestone 


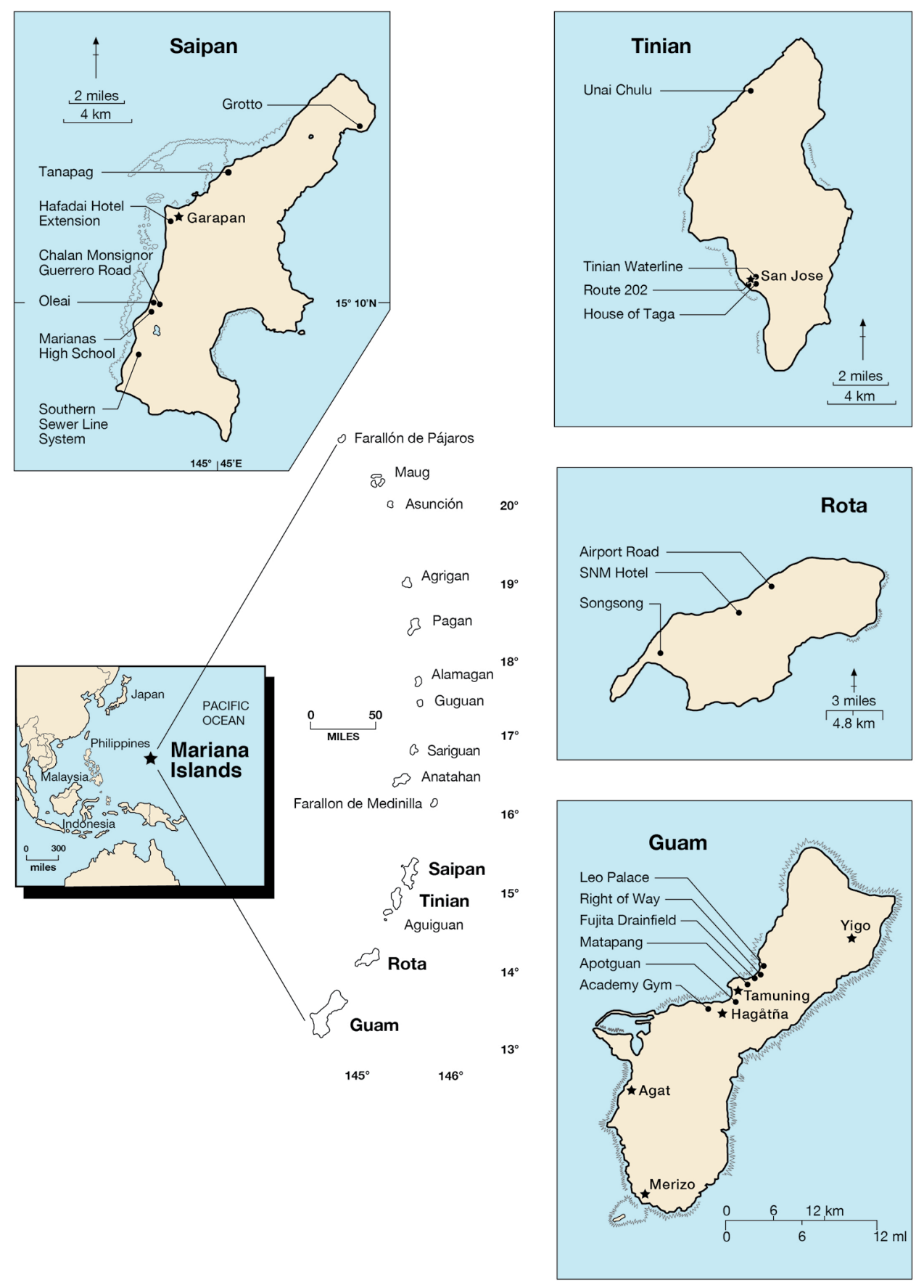

Fig. 1. Map of the Mariana Islands showing approximate locations of the skeletal series used in the present study. 
aquifers within the island mass fluctuates with the tides and may be intermittently accessible at springs and seeps in the coastal areas (Carruth 2003).

The marine tropical climate of the Mariana Islands is characterized by a pronounced summer monsoon, which often results in heavy rains, tropical storms, and typhoons (Hanson and Butler 1997; Tracey et al. 1964). There is little seasonal temperature change throughout the year and average monthly temperatures range from 20 to $30{ }^{\circ} \mathrm{C}$. Despite receiving high annual rainfall $(2000$ to $2500 \mathrm{~mm}$ ), the islands are subject to serious drought conditions during the dry season, often prolonged by the El Niño/Southern Oscillation (ENSO) phenomenon (Hunter-Anderson 2010). With the exception of Guam, surface water on the remaining islands is scarce, a situation that can lead to serious water shortages. Overall, these islands' susceptibility to droughts, severe tropical storms, and cyclones cause periodic devastation of reef systems and terrestrial vegetation, contamination of freshwater sources with seawater, and damage to other resources (Hunter-Anderson 2010, 2012). The larger Mariana Islands support tropical seasonal vegetation that ranges from grassland to moist forests. Humans, who introduced exotic plant and animal species, heavily impacted the native vegetation of these islands (Athens and Ward 2004).

\section{CHAMORRO PREHISTORY AND SUBSISTENCE}

Human occupation of the Mariana Islands began approximately 3500 B.P., most likely introduced from the Philippines and Island Southeast Asia (Athens et al. 2004; Carson 2012a, 2014; Dixon and Schaefer 2014; Fitzpatrick and Callaghan 2013; Hung et al. 2011; Hunter-Anderson 2010; Vilar et al. 2013). The prehistory of the Mariana Islands is traditionally divided into Pre-Latte, Transitional Pre-Latte, and Latte periods, following Moore (1990). Latte refer to paired stone pillars with cup-shaped capstones, which likely served as building supports (Carson 2012b; Davis et al. 1992; Graves 1986; Hanson and Butler 1997).

During the Pre-Latte period (1500 B.C.-A.D. 400), population size was small and concentrated in coastal villages, whose inhabitants relied on fishing, shellfish, and agricultural subsistence. The Transitional Pre-Latte period (A.D. 400-900) witnessed adaptive changes associated with increasing population size and an expansion of human settlement from the coast to the interior of the islands (Hunter-Anderson and Butler 1995 : 66). This expansion appears to have involved more intensive use of terrestrial resources with the effect of increasing the diversity of areas in which crops were raised. During the Latte period (A.D. 900-1700), in addition to the presence of latte structures in larger villages, other changes in technology allowed the settlement of inland areas of the larger islands. Recent genetic evidence suggests the people living during the Pre-Latte period were descendants of an earlier small founding group of migrants from Island Southeast Asia c. 4000 B.P. who were later joined by another migration from Island Southeast Asia c. 1000 B.P. (Vilar et al. 2013). There is overlap of the Latte period with the protohistoric period, which began with Ferdinand Magellan's historic landfall in Guam in 1521 and culminated with the forcible removal and relocation of most of the Chamorro to Guam in the late 1600s and early 1700s (Farrell 1991 : 176; Lévesque 1997 : 153-161, 182-199; Russell 1998:313-315).

The early inhabitants of the Mariana Islands undoubtedly faced environmental as well as geographical challenges. The remoteness of the islands, small landmasses, narrow non-continuous fringing reefs, volcanic eruptions, earthquakes, typhoons, and 
fluctuations in sea level and climate were among the challenges to successful occupation of these islands in the western Pacific. In addition to local environmental fluctuations, the early inhabitants faced greater regional changes in climate linked to the transition from the relatively warm, wet climate of the Medieval Warm Period (MWP, c. A.D. 800-1350) to the cooler, drier Little Ice Age (LIA, c. A.D. 1350-1900) (Hunter-Anderson 2010, 2012; Nunn 2007). In addition to cooler temperatures during the LIA, lower sea levels and increased weather systems likely increased periods of drought, requiring even greater cultural adjustment by these island inhabitants.

Although climate change and fluctuations in sea level and temperature are known to affect land use and subsistence economy, climate change during the Latte period in the Marianas may not have been as pronounced as in the central and eastern Pacific and other regions of the world during the transition to the LIA (Carson 2012b; Hunter-Anderson 2010, 2012; Nunn 2007). The subsistence economy of the Latte period, including horticulture and reliance on marine resources, may have allowed the Chamorro of this time period to be more tolerant of climatic change, including periodic typhoons (Carson 2012b; Hunter-Anderson 2010). The generally favorable and stable conditions of the MWP may have resulted in population expansion and more intense utilization of inland and coastal regions (Carson 2012b; Hunter-Anderson 2010, 2012).

Pre-Contact Chamorro subsistence economies included cultivated tree and root crops typical of the tropical island environment such as coconut, banana, breadfruit, taro, yam, and possibly rice - foods that tend to be high in carbohydrates. Likewise, the early Chamorro gathered and hunted endemic migratory birds, native fruit bats, turtles, and crabs (Butler 1990; Dixon et al. 2003:17; Hunter-Anderson and Butler 1995; Russell 1998:179). Commensal species, such as rats, arrived in the islands during the Latte period, but others such as pig, dog, and chicken, frequently associated with the initial colonizers of other parts of Remote Oceania, were missing (Carson $2012 b: 58)$. Early Chamorro supplemented terrestrial-based economies with marine resources, including fish and shellfish, found in the surrounding reefs, reef flats, and deep-water environments (Alkire 1977: 7; Butler 1988:16).

\section{PREVIOUS RESEARCH IN BIOARCHAEOLOGY OF THE MARIANA ISLANDS AND THIS STUDY}

Previous (Douglas et al. 1997; Hanson and Butler 1997; Pietrusewsky et al. 1997) and more recent (Pietrusewsky et al. 2010, 2011, 2014) work in the Mariana Islands has established general findings on health and disease. The ancient Chamorro were medium to tall statured people with good oral-dental health and strong robust bones reflecting active use of the limbs in both sexes. They suffered from leprosy, gout, and treponemal infection, which was likely endemic in the islands from the Latte period into the historic period (Pietrusewsky et al. 1997; Pietrusewsky et al. 2007; Rothschild and Heathcote 1993; Stewart and Spoehr 1952; Trembly 1995, 1996). A stress fracture of the lumbar spine (spondylolysis) occurred at a very high rate in the prehistoric Chamorro sample (Arriaza 1997), which is consistent with extreme physical exertion such as required for quarrying and building limestone latte sets. Slight osteoarthritis was predominant in both sexes but advanced osteoarthritis was more common in females than males in a large skeletal series from Apotguan (Apurguan), Guam, suggesting activity pattern differences (Douglas et al. 1997). Sex differ- 
ences in oral-dental pathology were noted in the Apotguan series, including significantly higher rates of periapical abscesses and alveolar resorption and attrition in females.

A second large skeletal series $(n=482)$ from Guam (i.e., the Hyatt Hotel site on Tumon Bay) has only recently become available to address questions of sex differences in health (Ryan 2010; Stodder et al. 2016; Trembly and Tucker 1999). Using data provided in Trembly and Tucker (1999), no statistically significant sex differences were found in the rates of cribra orbitalia (CO), spondylolysis, or treponemal infection. Linear enamel hypoplasia (LEH) in the canines and incisors was significantly greater in male teeth (17.1\%) than in female teeth $(8.7 \%)$. Betel-stained teeth were significantly more common in females (80.2\%) than males (63.9\%). Antemortem tooth loss (AMTL) was significantly greater in males, while females had significantly more dental calculus. No significant differences were noted in other dental pathologies (e.g., caries and attrition). Long limb bone fractures were noted in three females with an incidence (calculated from length measurements) of 3/212 (1.4\%), but no long limb bone fractures occurred in males (0/195); other traumas were described in both sexes (Trembly and Tucker 1999:37-41).

Pietrusewsky and colleagues (2014) recently summarized health and lifestyle indicators and examined interisland differences in 385 skeletons, sexes combined, from 22 sites on all 4 of the main islands, the largest data assemblage from the Marianas to date. Findings included interisland similarities in stature, long limb bone fractures, spondylolysis, and alveolar defects. Childhood stress, reflected in frequencies of CO and $\mathrm{LEH}$, was greater on the more northern islands of Tinian and Saipan, while treponemal disease was highest on the smaller island of Rota (perhaps due to sample size). The oral-dental indicators varied between the islands, the outcome influenced by the cultural habit of betel nut chewing, which was more common on the northern islands. To further investigate interisland differences, we examine sex differences in the prevalence of these markers of health and disease for each of the main four islands and then for all the islands combined.

\section{SKELETAL SERIES}

A total of 333 sexed adult skeletons from 21 primarily coastal sites on Guam, Rota, Tinian, and Saipan of the Mariana Islands are included in this study (Fig. 1; Table 1). Assembled over more than three decades from cultural resource management projects, all of the skeletons in this analysis were examined by the authors except for two samples from Rota that we believe utilized very similar methods. The majority of these skeletons are from the Latte period (A.D. 900-1700), but a few (e.g., from the Fujita and Matapang sites on Guam) are from the Transitional Pre-Latte period (A.D. 400-900).

There are typically more males than females in most skeletal series and the sex ratio is skewed heavily toward males for Saipan. Overall, young (20-34) and middle-aged (35-49) adults are equally represented, although the Saipan series has an older age-atdeath profile $(60.5 \%$ middle-aged or old [50+ years]), followed by the Guam series (46.0\% middle-aged or old-aged). Approximately 9 percent of all adults died during old age. The San Antonio skeletal series analyzed in earlier studies of health and disease in the Mariana Islands is omitted from this study because preservation and completeness prohibited sex estimates (Pietrusewsky et al. 1997; Pietrusewsky et al. 2014). 


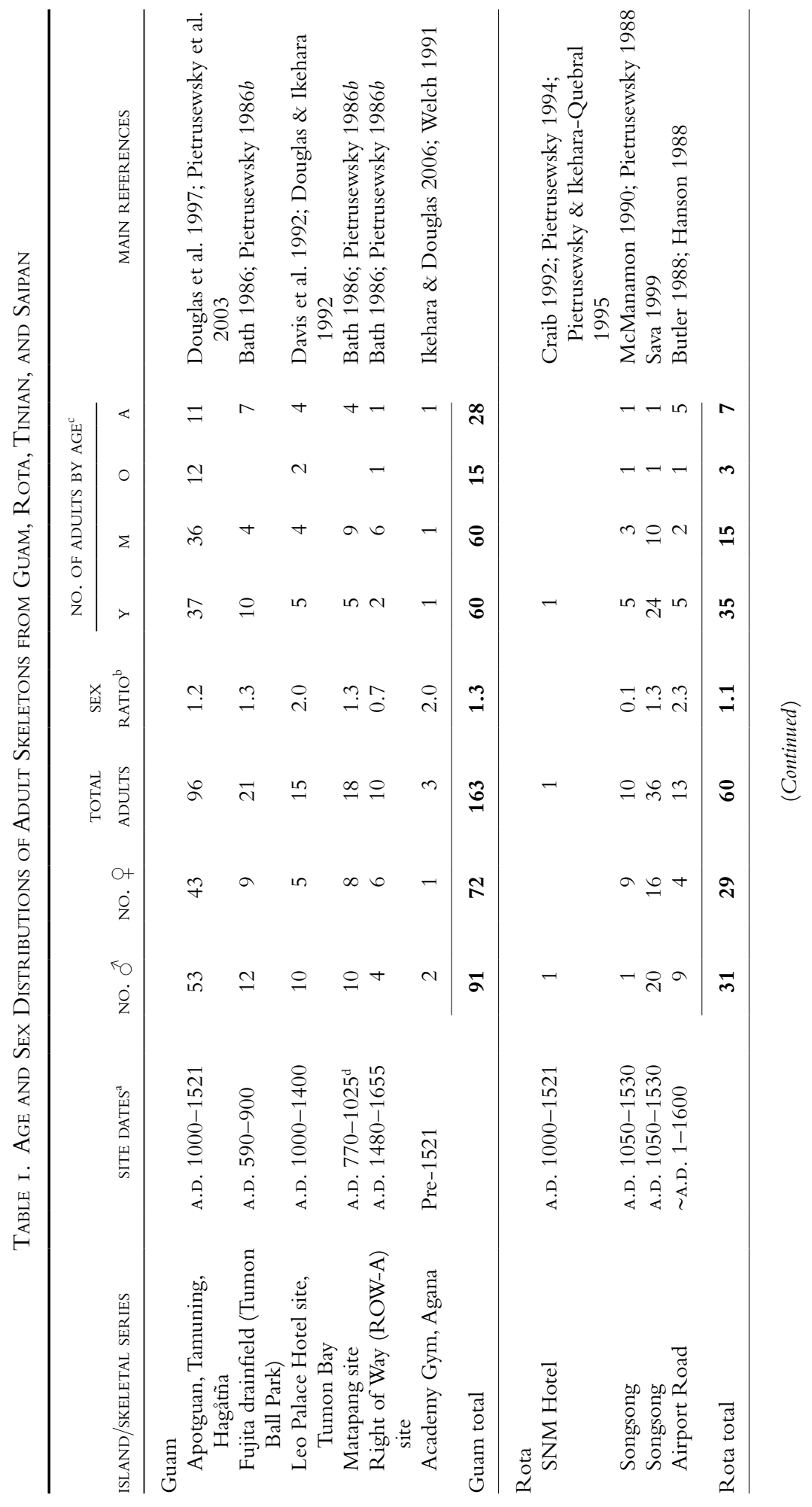




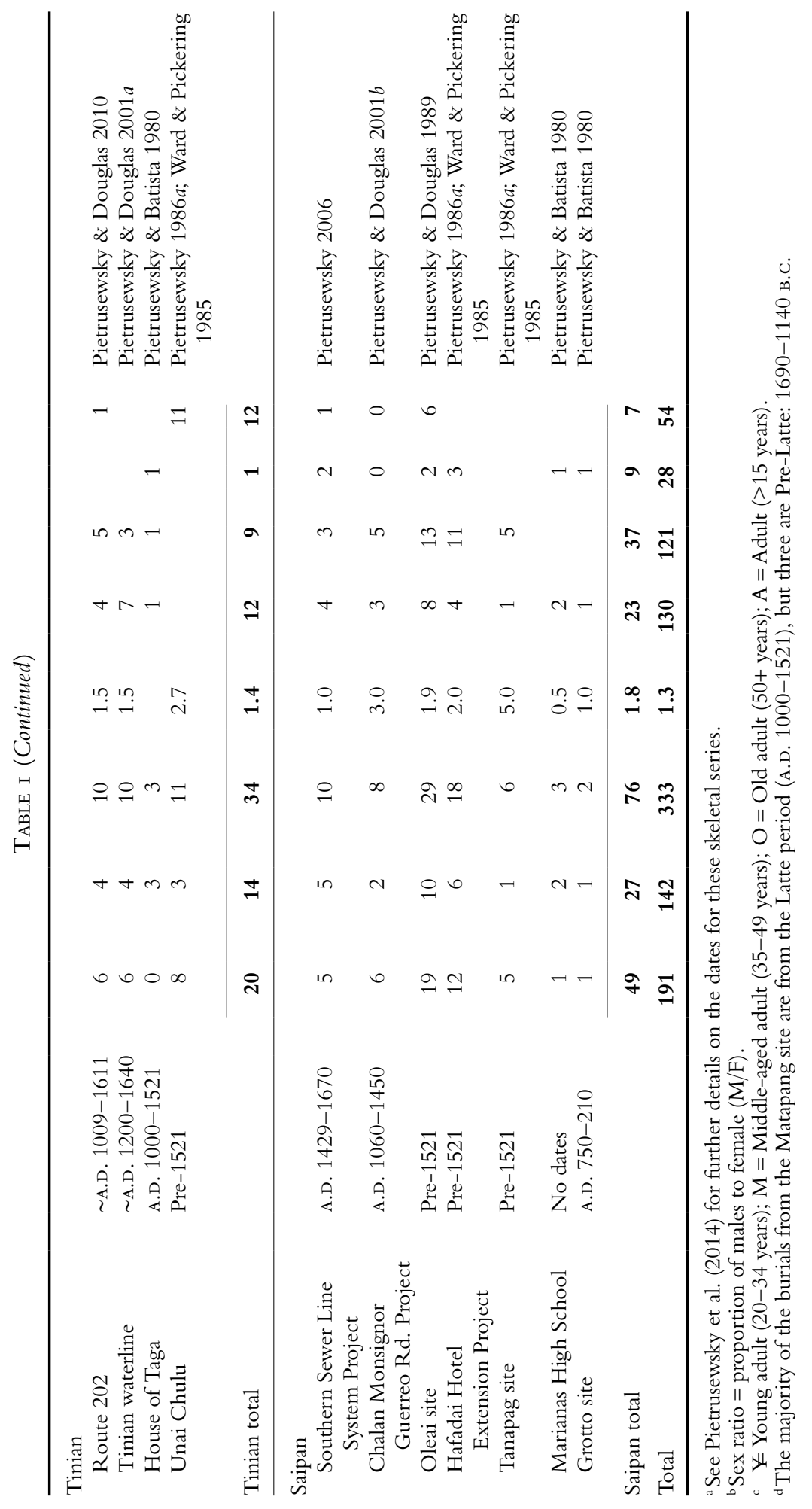




\section{METHODS}

Standard osteological methods were used to estimate sex and age-at-death (Buikstra and Ubelaker 1994; Pietrusewsky and Douglas 2002). The skeletal and dental indicators of health investigated include those attributable to non-specific systemic stress during growth and development (e.g., LEH and CO) and those that suggest specific stressors (e.g., trauma, infection, and dental disease). With the exception of the Airport Road site on Rota, the data used in this article were recorded by Pietrusewsky and those who were trained by him, thus minimizing inter-observer error. Fisher's exact test was used to test for significant differences in the discontinuous data and Student's t-test for continuous data (Thomas 1986).

The contributions of the co-authors are as follows: M.P. and M.T.D. designed research, recorded data for the research, analyzed data, and wrote this article. M.K.S., R.A.H., and M.A.F. excavated key skeletal samples and associated cultural materials from Tinian and Saipan and contributed to interpretations of the data and writing the article.

\section{Cribra Orbitalia (CO)}

Cribra orbitalia (CO), characterized by sieve-like lesions that develop in the orbital roofs, is commonly attributed to iron deficiency anemia (Oxenham and Cavill 2010; Stuart-Macadam 1989, 1991) or megaloblastic anemia (Walker et al. 2009). In this study the frequency of $\mathrm{CO}$ is reported by individual.

\section{Linear Enamel Hypoplasia (LEH)}

Linear enamel hypoplasia (LEH), observable as one or more transverse furrows or grooves of varying depths on the crown surfaces of teeth, is generally linked to the disruption of enamel development during infancy and early childhood (Goodman and Rose 1990, 1991). A variety of stressors, including malnutrition, metabolic disorders, acute and chronic infections, physical trauma, and hereditary conditions that affect the mother and/or growing child can disrupt enamel production (Goodman et al. 1984; Goodman and Rose 1990, 1991; Hillson 2008). Because defects are more frequent in the incisor and canine teeth, we report any manifestation of LEH, regardless of the number of defects or their severity, on a presence/absence basis for these teeth only.

\section{Stature}

Because of the lack of population-specific stature formulae for Chamorro skeletons the stature estimates are based on formulae for New Zealand Maori (Houghton et al. 1975) using the maximum and/or physiological length measurements for adult males and females. If more than one stature estimate was calculated, the estimate having the least error was selected.

\section{Limb Bone Fractures}

Major limb bone fractures (clavicle, humerus, radius, ulna, femur, tibia, and fibula) provide an indication of the frequency and type of traumatic, accidental, or deliberate 
injury in a population (Lovell 2008; Walker 1989). Although healed fractures of other bones in the skeleton, including the skull, are observed in Mariana skeletons, because of difficulties in establishing frequencies in these kinds of fractures, we focus on the long limb bones. The frequency of fractures is estimated using the corresponding number of complete, or nearly complete, bones reported.

\section{Spondylolysis}

Spondylolysis is a non-displaced stress fracture of the vertebrae occurring at the pars interarticularis (the part of the vertebra between the superior and inferior facets). This type of fracture is often related to repeated stress to the lower lumbar vertebrae by physical activities requiring flexion of the lumbar spine with the legs extended (Merbs 1996; Ortner 2003). Arriaza (1997) proposed hyperextension of the lower back under stressful conditions, such as in latte construction, as a possible explanation for spondylolysis. The frequency of spondylolysis is based on the number of lumbar vertebrae observed.

\section{Infection}

Treponemal infections including pinta, yaws, and syphilis are caused by the spirochete Treponema pallidum. Of these, only yaws and syphilis affect the skeleton, producing lesions of the cranial vault, as well as symmetrical appositional lesions of the long limb bones (Ortner 2003).

It is widely acknowledged that venereal syphilis was absent in the Mariana Islands and the Pacific prior to contact with Europeans (Baker and Armelagos 1988; Stewart and Spoehr 1952), leaving yaws as the treponemal infection most likely responsible for bony lesions observed in skeletons from this region of the world before the historic period (Rothschild and Heathcote 1993). Bony changes attributed to treponemal infection, such as periosteal reaction, gummatous osteitis, and cloacae, were observed in the skeletons from the Mariana Islands. Here, we report the frequency of treponemal infection by individual.

\section{Dental Modification and Pathology}

Betel-stained teeth and dental pathology are scored on a "per tooth/per socket" basis and are reported in adults ( $>15$ years) with sex estimates. The staining of the tooth enamel in the skeletons from the Mariana Islands is usually light to dark brown/ reddish brown in color and typically involves buccal and lingual surfaces, to varying degrees, of all permanent teeth in the maxillary and mandibular dentitions. This pattern suggests the staining is due to chewing of betel nut rather than the intentional blackening of the labial/buccal surfaces of the anterior teeth observed in Asia and elsewhere (Hanson and Butler 1997; Oxenham et al. 2002).

Dental Caries - Dental caries is a demineralization of the tooth structures caused by organic acids produced by bacterial processes involved in the fermentation of dietary carbohydrates (Hillson 2008:313). Dental caries are scored on a presence/absence basis.

Alveolar Defects - Alveolar defects are loss of alveolar bone around the apex of the tooth roots, originating from infections of the pulp. The term "alveolar defect" 
replaces "dental abscess" used in previous studies (e.g., Pietrusewsky et al. 1997; Steckel and Rose 2002). Alveolar defects are scored on a presence/absence basis.

Dental Calculus - Dental calculus, which is enhanced by high carbohydrate diets, is calcified or mineralized dental plaque (Hillson 2008; Lieverse et al. 2007). A number of variables are responsible for the mineralization of plaque including an alkaline oral environment, "salivary flow rate, hydration, calcium and phosphate levels in the blood, mineral content of drinking water, silicon content in both food and water, and plaque accumulation" (Lieverse 1999; Lieverse et al. 2007:332).

Of the two forms of calculus generally recognized (Hillson 2008; Lieverse 1999; White 1997), we report only supragingival calculus, which is observed on the tooth crowns and sometimes roots. In the skeletons from the Mariana Islands, dental calculus was mainly confined to the tooth crown and cemento-enamel junction. In this study, we report the overall frequency of advanced (moderate and marked) calculus (Brothwell 1981:155).

Dental Attrition - Dental attrition results from tooth-on-tooth contact, which produces wear facets on the occlusal and proximal surfaces of the teeth in function (Hillson 1996). In the skeletons from the Mariana Islands, occlusal attrition was recorded on an absent, slight (enamel wear), moderate (dentin exposure), and marked (pulp exposure) gradient. Here, we report only moderate and marked expressions of dental attrition.

Antemortem Tooth Loss (AMTL) - Antemortem tooth loss (AMTL), or the loss of teeth before death, can be attributed to several pathological processes including periodontal disease, carious lesions, and alveolar defects (Lukacs 2007; Mays 2010). The principal criterion for recognizing AMTL is alveolar bone remodeling following the loss of teeth during life.

\section{RESULTS}

The cultural practice of chewing betel quid influences many of the dental health indicators and has proven to complicate interpretations of oral health in the Mariana Islands. For example, caries rates in other groups are often consistent enough to suggest a subsistence economy, but betel quid (including the seed of the areca palm, Areca catechu, leaf of Piper betle, and possibly powdered limestone) is cariostatic and also affects the prevalence of calculus, attrition, and periodontal disease (Howden 1984; Schamschula et al. 1977; Trivedy et al. 2002). Because of these complications, the health indicators will be examined in two parts: first LEH, CO, trauma, and infection, then dental pathology.

The first question that we address is whether there are differences in health between the sexes and, if so, whether the sex differences are consistent across the islands. We then examine differences in male and female health between the islands using stature, $\mathrm{LEH}, \mathrm{CO}$, spondylolysis, limb bone fracture, infection, and dental pathology.

\section{Are There Differences in Health between the Sexes?: LEH, CO, Trauma, and Infection}

Guam: Guam, the largest of the islands and the source of the largest number of skeletons, presents no statistically significant sex differences in frequencies of LEH, CO, 
Table 2. LeH, CO, Spondylolysis, Limb Bone Fracture, and Treponemal Infection in Adult Skeletons from Guam, Rota, Tinian, and Saipan

\begin{tabular}{|c|c|c|c|c|c|}
\hline & \multicolumn{2}{|c|}{ MALE } & \multicolumn{2}{|c|}{ FEMALE } & \multirow[b]{2}{*}{$\mathrm{FET}^{\mathrm{b}}$} \\
\hline & $\mathrm{A} / \mathrm{O}^{\mathrm{a}}$ & $\%$ & $\mathrm{~A} / \mathrm{O}$ & $\%$ & \\
\hline \multicolumn{6}{|l|}{$\mathrm{LEH}^{c}$} \\
\hline Guam & $58 / 181$ & 32.0 & $36 / 135$ & 26.7 & 0.3217 \\
\hline Rota & $22 / 79$ & 27.8 & $22 / 79$ & 27.8 & 1.000 \\
\hline Tinian & $2 / 70$ & 2.9 & $7 / 31$ & 22.6 & $0.0033 *$ \\
\hline Saipan & $31 / 49$ & 63.3 & $13 / 33$ & 39.4 & $0.0432 *$ \\
\hline Total & $113 / 379$ & 29.8 & $78 / 278$ & 28.1 & 0.6640 \\
\hline \multicolumn{6}{|l|}{$\mathrm{CO}^{\mathrm{d}}$} \\
\hline Guam & $3 / 25$ & 12.0 & $0 / 17$ & 0.0 & 0.2596 \\
\hline Rota & $1 / 7$ & 14.3 & $0 / 11$ & 0.0 & 0.3889 \\
\hline Tinian & $4 / 10$ & 40.0 & $3 / 10$ & 30.0 & 1.000 \\
\hline Saipan & $10 / 38$ & 26.3 & $2 / 19$ & 10.5 & 0.3012 \\
\hline Total & $18 / 80$ & 22.5 & $5 / 57$ & 8.8 & $0.0386^{*}$ \\
\hline \multicolumn{6}{|c|}{ Spondylolysis } \\
\hline Guam & $9 / 105$ & 8.6 & $1 / 44$ & 2.3 & 0.2821 \\
\hline Rota & $2 / 33$ & 6.1 & $0 / 29$ & 0.0 & 0.4939 \\
\hline Tinian & $1 / 27$ & 3.7 & $0 / 9$ & 0.0 & 1.000 \\
\hline Saipan & $1 / 23$ & 4.3 & $0 / 11$ & 0.0 & 1.000 \\
\hline Total & $13 / 158$ & 8.2 & $1 / 93$ & 1.1 & $0.0201 *$ \\
\hline \multicolumn{6}{|c|}{ Limb Bone Fracture ${ }^{f}$} \\
\hline Guam & $2 / 307$ & 0.7 & $3 / 298$ & 1.0 & 0.6819 \\
\hline Rota & $1 / 54$ & 1.9 & $1 / 170$ & 0.6 & 0.4248 \\
\hline Tinian & $2 / 75$ & 2.7 & $0 / 118$ & 0.0 & 0.1498 \\
\hline Saipan & $1 / 130$ & 0.8 & $1 / 101$ & 1.0 & 1.000 \\
\hline Total & $6 / 566$ & 1.1 & $5 / 687$ & 0.7 & 0.5563 \\
\hline \multicolumn{6}{|c|}{ Treponemal Infection ${ }^{\mathrm{g}}$} \\
\hline Guam & $8 / 91$ & 8.8 & $5 / 72$ & 6.9 & 0.7755 \\
\hline Rota & $4 / 22$ & 19.0 & $7 / 26$ & 26.9 & 0.5145 \\
\hline Tinian & $1 / 12$ & 8.3 & $1 / 11$ & 9.1 & 1.000 \\
\hline Saipan & $3 / 32$ & 9.4 & $2 / 20$ & 10.0 & 1.000 \\
\hline Total & $16 / 157$ & 10.2 & $15 / 129$ & 11.6 & 0.7068 \\
\hline
\end{tabular}

${ }^{a} \mathrm{~A} / \mathrm{O}=$ affected/observed

${ }^{\mathrm{b}} \mathrm{FET}=$ Fisher's Exact Test, two-tailed test $; *$ indicates statistically significant values.

${ }^{\mathrm{c}} \mathrm{LEH}=$ linear enamel hypoplasia scored by tooth (incisors and canines).

${ }^{\mathrm{d}} \mathrm{CO}=$ cribra orbitalia scored by individual.

e Spondylolysis is scored by lumbar vertebrae.

${ }^{\mathrm{f}} \mathrm{Limb}$ bone fracture reported by bone.

${ }^{\mathrm{g}}$ Treponemal infection reported in individuals.

spondylolysis, limb bone fractures, or treponemal disease (Table 2). However, the indicators of childhood stress and infection are more common in males than females, and, as expected, spondylolysis is more common in males than females.

Rota: The island of Rota is quite close to Guam, which suggests that some of the people living on these two islands are genetically related. As is the case for Guam, no significant sex differences are noted in frequencies of childhood stress, fracture, or infection in the Rota skeletal series. Fractures are more common in males, while 
treponemal infection is more common in females; childhood stress indicators are comparable for both sexes.

Tinian: Although fractures and $\mathrm{CO}$ are more common in males from Tinian than in females, the only significant sex difference is in LEH, signifying stress in early childhood, which is nearly ten times greater in females than males.

Saipan: The trend for greater indicators of stress in males continues in the Saipan series, with males exhibiting significantly higher frequencies of LEH than females. $\mathrm{CO}$ and fractures are also higher in males than females, while frequencies of infection are nearly identical for both sexes.

There are no statistically significant differences in male and female health on Guam and Rota. Only one statistically significant difference between the sexes is noted on Tinian and Saipan, that is, frequencies of LEH are greater in Tinian females and Saipan males. The small sample sizes for observations of CO and spondylolysis may be influencing these results. When analyzed per island, these two health indicators are consistently greater in males compared to females, but the differences are significant only in the combined islands sample. Overall, the lack of significant island-specific differences in these indicators of health suggests equality between the sexes in the risks of infection and bone fractures for all islands. For Tinian and Saipan there are differences between the sexes in childhood health.

\section{Are Sex Differences Consistent across the Islands?: LEH, CO, Trauma, and Infection}

With the exception of LEH noted above, differences between sexes are consistent across the islands. Although not statistically significant, males generally have higher frequencies of $\mathrm{CO}$, long limb bone fractures, and spondylolysis, while females have higher frequencies of treponemal infection. However, when all the island series are combined, which minimizes sample size issues, there are no significant differences in $\mathrm{LEH}$ between the sexes, but the frequencies of $\mathrm{CO}$ and spondylolysis are significantly greater in males (Fig. 2, Table 2).

\section{Are There Differences in Health between the Sexes?: Dental Indicators}

Guam: Guam males have a significantly higher frequency of betel staining than females (Table 3). The only additional significant difference between sexes is a higher frequency of alveolar defects in females.

Rota: For Rota, males have significantly more dental caries than females, in spite of the significantly greater frequency of betel staining in males, which should have a cariostatic effect. Extensive betel chewing may contribute to extreme dental attrition, promoting carious infection through the exposed pulp cavity. An alternative explanation, although difficult to prove, is that the staining in male teeth may be due to intentional staining (i.e., the staining is not due to betel chewing), which does not convey a cariostatic effect.

Tinian: Three indicators of oral-dental health are significantly different between the sexes in the Tinian sample: caries, alveolar defects, and attrition are all greater in females than in males. This pattern is unexpected given the cariostatic nature of betel chewing, which is also significantly more common in Tinian females; however, severe attrition observed in the female teeth from Tinian can also result in caries and subsequent alveolar defects. 


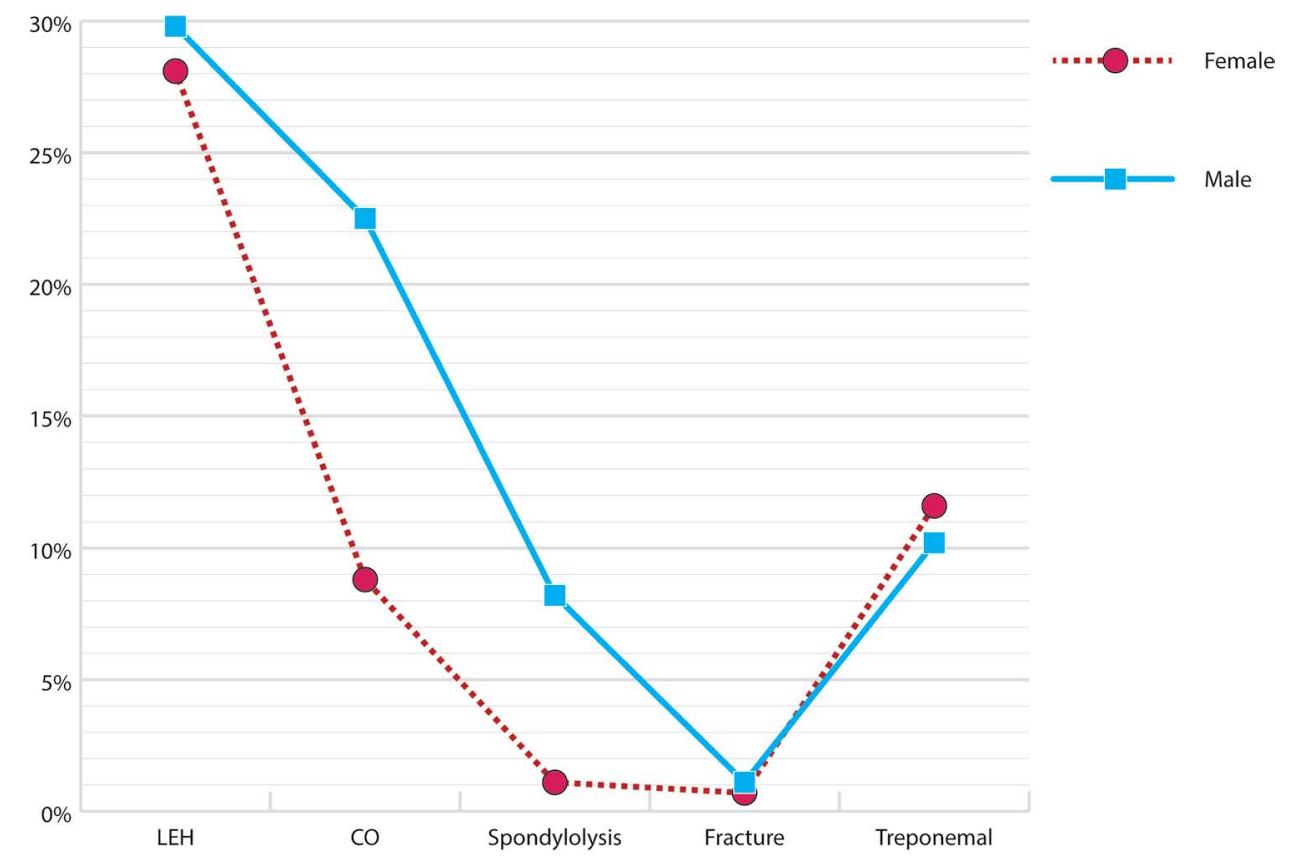

Fig. 2. Frequency of occurrence of linear enamel hypoplasia (LEH), cribra orbitalia (CO), spondylolysis, limb bone fracture, and treponemal infection in female and male skeletons from the Mariana Islands.

Saipan: Saipan sex differences in dental indicators show significantly greater betel staining and attrition in female teeth and significantly fewer carious teeth than males, a pattern that is consistent with betel quid chewing.

Overall, there are fewer island-specific differences in the frequencies of dental pathologies between the sexes for Guam, Rota, and Saipan, when compared to Tinian. The Tinian series shows significantly greater frequencies of caries, alveolar defects, and attrition observed in females. The relatively small sample size for this island may account for these sex differences, although the combined island totals suggest these differences are real (see discussion below). Other significant differences between the sexes are observed for betel staining. Guam and Rota males have significantly higher frequencies of staining than females from these islands, while females have greater betel staining than males on Tinian and Saipan. These differences are very likely influencing some of the other dental health indicators. Regardless of the island, there are no significant differences between the sexes in the frequencies of AMTL and dental calculus.

\section{Are Sex Differences Consistent across the Islands?: Dental Indicators}

AMTL and dental calculus frequencies are consistent across the islands, showing no significant differences between the sexes. However, betel staining shows significant sex differences for all islands; it is greater in males from Guam and Rota and greater in females from Tinian and Saipan. Where there is a significant difference, frequencies of alveolar defects and attrition are higher in females across the islands. Caries rates 
Table 3. Betel Staining and Dental Pathology (Scored by Tooth) in Adult Dentitions From Guam, Rota, Tinian, AND SAIPAN

\begin{tabular}{|c|c|c|c|c|c|}
\hline & \multicolumn{2}{|c|}{ MALE } & \multicolumn{2}{|c|}{ FEMALE } & \multirow[b]{2}{*}{$\mathrm{FET}^{\mathrm{b}}$} \\
\hline & $\mathrm{A} / \mathrm{O}^{\mathrm{a}}$ & $\%$ & $\mathrm{~A} / \mathrm{O}$ & $\%$ & \\
\hline \multicolumn{6}{|c|}{ Betel Staining } \\
\hline Guam & $682 / 1200$ & 56.8 & $383 / 766$ & 50.0 & $0.0034^{*}$ \\
\hline Rota & $136 / 214$ & 63.6 & $170 / 314$ & 54.1 & $0.0388^{*}$ \\
\hline Tinian & $152 / 227$ & 67.0 & $162 / 162$ & 100.0 & $0.0001 *$ \\
\hline Saipan & $194 / 281$ & 69.0 & $205 / 277$ & 90.3 & $0.0001 *$ \\
\hline Total & $1164 / 1422$ & 60.6 & $920 / 1469$ & 62.6 & $0.0001 *$ \\
\hline \multicolumn{6}{|l|}{ AMTL } \\
\hline Guam & 76/979 & 7.8 & $62 / 707$ & 8.8 & 0.4722 \\
\hline Rota & $27 / 302$ & 8.9 & $21 / 293$ & 7.2 & 0.4547 \\
\hline Tinian & $7 / 277$ & 2.5 & $2 / 173$ & 1.2 & 0.4926 \\
\hline Saipan & $31 / 403$ & 7.7 & $14 / 314$ & 4.5 & 0.0881 \\
\hline Total & $141 / 1961$ & 7.2 & $99 / 1487$ & 6.7 & 1.0000 \\
\hline \multicolumn{6}{|l|}{ Caries } \\
\hline Guam & $53 / 1188$ & 4.5 & $32 / 802$ & 4.0 & 0.8209 \\
\hline Rota & $40 / 222$ & 18.0 & $19 / 312$ & 6.1 & $0.0001^{*}$ \\
\hline Tinian & $0 / 226$ & 0.0 & $17 / 146$ & 11.6 & $0.0001 *$ \\
\hline Saipan & $24 / 275$ & 8.7 & $8 / 229$ & 3.5 & $0.0172 *$ \\
\hline Total & $117 / 1911$ & 6.1 & $76 / 1489$ & 5.1 & 0.2320 \\
\hline \multicolumn{6}{|c|}{ Alveolar Defects } \\
\hline Guam & $38 / 1020$ & 3.7 & $43 / 651$ & 6.6 & $0.0098^{*}$ \\
\hline Rota & $16 / 211$ & 7.6 & $19 / 268$ & 7.1 & 0.8611 \\
\hline Tinian & $2 / 157$ & 1.3 & $7 / 80$ & 8.8 & $0.0078^{*}$ \\
\hline Saipan & $19 / 248$ & 7.7 & $10 / 187$ & 5.3 & 0.4381 \\
\hline Total & $75 / 1636$ & 4.6 & 79/1186 & 6.7 & $0.0186^{*}$ \\
\hline \multicolumn{6}{|l|}{ Calculus $^{c}$} \\
\hline Guam & $182 / 1165$ & 15.6 & $129 / 780$ & 16.5 & 0.6137 \\
\hline Rota & $69 / 212$ & 32.5 & $74 / 287$ & 25.8 & 0.1093 \\
\hline Tinian & $35 / 215$ & 16.4 & $12 / 118$ & 10.2 & 0.1408 \\
\hline Saipan & $35 / 258$ & 13.6 & $15 / 189$ & 7.9 & 0.0691 \\
\hline Total & $321 / 1850$ & 17.4 & $230 / 1374$ & 16.7 & 0.6704 \\
\hline \multicolumn{6}{|l|}{ Attrition $^{d}$} \\
\hline Guam & $341 / 1230$ & 27.7 & 212/792 & 26.8 & 0.6459 \\
\hline Rota & $68 / 212$ & 32.1 & $85 / 311$ & 27.3 & 0.2423 \\
\hline Tinian & $61 / 226$ & 27.0 & $113 / 144$ & 78.5 & $0.0001 *$ \\
\hline Saipan & $140 / 291$ & 48.1 & $145 / 236$ & 61.4 & $0.0028^{*}$ \\
\hline Total & $610 / 1959$ & 31.1 & $555 / 1483$ & 37.4 & $0.0001^{*}$ \\
\hline
\end{tabular}

${ }^{\mathrm{a}} \mathrm{A} / \mathrm{O}=$ affected/observed.

${ }^{\mathrm{b}} \mathrm{FET}=$ Fisher's Exact Test, two-tailed test; * indicates statistically significant values.

${ }^{\mathrm{c}}$ Moderate and marked expressions of calculus are reported.

${ }^{\mathrm{d}}$ Moderate (reaching the dentin) and marked (pulp exposure) attrition are reported. 


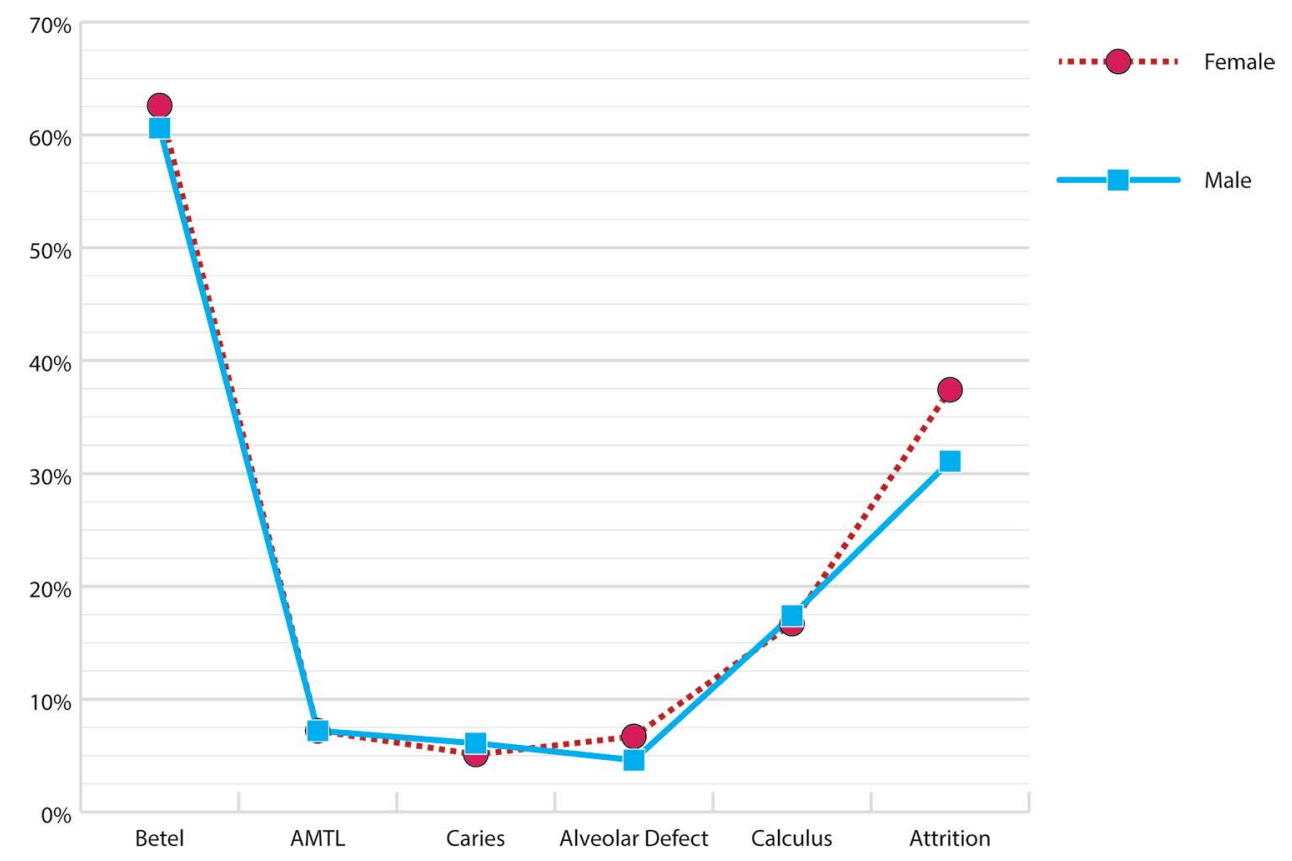

Fig. 3. Frequency of occurrence of betel-stained teeth, antemortem tooth loss (AMTL), dental caries, alveolar defect, dental calculus, and dental attrition in female and male skeletons from the Mariana Islands.

vary the most: significantly higher caries rates are noted in males from Rota and Saipan and in females from Tinian.

When the frequencies from all four islands are combined, significant differences between the sexes are noted: betel staining, alveolar defects, and attrition are all higher in females (Fig. 3, Table 3).

\section{Are There Differences in Male Health between Islands?: Stature, LEH, CO, Trauma, and Treponemal Infection}

Comparison of average male statures for the four main islands reveals no significant differences between any of the islands (Table 4). Very similar mean male statures are reported for Guam and Rota $(172 \mathrm{~cm})$, approximately $2 \mathrm{~cm}$ less than the mean male statures for Tinian and Saipan. The tallest individual males are found on Saipan $(182 \mathrm{~cm})$, Rota $(179 \mathrm{~cm})$, and Tinian $(178 \mathrm{~cm})$. The average male stature for Marianas skeletons is $173 \mathrm{~cm}, 13 \mathrm{~cm}$ greater than the average for living Chamorro males from Saipan measured by Kotondo Hasebe (1938).

A summary of FET results for males indicates no significant differences in the frequencies of $\mathrm{CO}$, spondylolysis, limb bone fractures, or treponemal infection between islands (Table 5). However, with the exception of Rota (27.8\%) and Guam (32\%), significant differences in male frequencies of LEH were observed between the four main Mariana Islands. The wide disparity in the frequency of LEH for the remaining islands is due, in large measure, to the high frequency (63.3\%) in Saipan skeletons and the extremely low frequency $(2.9 \%)$ in Tinian skeletons. 
Table 4. Male Stature (cm) for the Skeletons from the Mariana Islands (4a); Two-Tailed $p$ Values Obtained from Unpaired t-Tests Comparing Stature BeTWEEN IsLANDS $(4 \mathrm{~b})$

$4 a$.

\begin{tabular}{lrccc}
\hline ISLAND & N & MEAN & MINIMUM & MAXIMUM \\
\hline Guam & 20 & 172.5 & 166.8 & 177.1 \\
Rota & 10 & 172.2 & 167.4 & 178.6 \\
Tinian & 9 & 174.0 & 168.7 & 178.1 \\
Saipan & 19 & 173.9 & 166.1 & 182.1 \\
\cline { 2 - 5 } Total & 58 & 173.2 & 166.1 & 182.1 \\
\hline
\end{tabular}

Note: Stature estimates were made using Houghton et al. (1975) formulae.

$4 \mathrm{~b}$.

\begin{tabular}{|c|c|c|c|c|}
\hline & GUAM & ROTA & TINIAN & SAIPAN \\
\hline Guam & - & 0.8004 & 0.2757 & 0.2649 \\
\hline Rota & & - & 0.2023 & 0.2612 \\
\hline Tinian & & & - & 0.9929 \\
\hline Saipan & & & & - \\
\hline
\end{tabular}

Note: All $p$ values are considered not to be statistically significant (95\% confidence interval).

Overall, with the exception of LEH (a childhood indicator of health) there are few differences in male health between islands, with Guam and Rota the most similar (Fig. 4). The frequencies of CO, fractures, spondylolysis, and infection are uniformly low in males. The average frequency of LEH (29.8\%) in males is moderately high compared to the other indicators.

\section{Are There Differences in Male Health between Islands?: Dental Indicators}

Comparisons of male frequencies of betel staining and dental pathology reveal numerous significant differences between islands (Fig. 5, Table 5). Many of these differences occur between Guam and Saipan, Rota and Tinian, and between Saipan and Tinian. The greatest number of inter-island differences is observed for dental caries and alveolar defects. Overall, there is less interisland variability for betel-stained teeth than for dental pathology. The results of comparing frequencies of dental pathology suggest differences in male health.

\section{Are There Differences in Female Health between Islands?: Stature, LEH, CO, Trauma,} and Treponemal Infection

Comparison of average female statures reveals no significant differences between any of the islands (Table 6). The mean stature for females from Guam is approximately $2 \mathrm{~cm}$ greater than the mean statures for Rota, Tinian, and Saipan. The tallest individual female is found on Rota $(171 \mathrm{~cm})$. Overall, the average Mariana Island female stature is $161 \mathrm{~cm}$, nearly $13 \mathrm{~cm}$ shorter than the average male stature. 
Table 5. Fisher's Exact Test (FET) Values for Interisland Comparisons of Male Health Indicators

5a. FET Values for CO (above) and LEH (below)

\begin{tabular}{lcccr}
\hline & GUAM & ROTA & TINIAN & SAIPAN \\
\hline Guam & & 1.000 & 0.1554 & 0.2145 \\
Rota & 0.5603 & $<0.0001^{*}$ & 0.3382 & 0.6628 \\
Tinian & $<0.0001^{*}$ & $=0.0001^{*}$ & $<0.0001^{*}$ & 0.4480 \\
Saipan & $=0.0001^{*}$ & & \\
\hline
\end{tabular}

5b. FET Values for Long Limb Bone Fractures (above) and Spondylolysis (below)

\begin{tabular}{|c|c|c|c|c|}
\hline & GUAM & ROTA & TINIAN & SAIPAN \\
\hline Guam & & 0.3859 & 0.1744 & 1.000 \\
\hline Rota & 1.000 & & 1.000 & 0.5020 \\
\hline Tinian & 0.6864 & 1.000 & 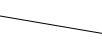 & 0.5556 \\
\hline Saipan & 0.6890 & 1.000 & 1.0000 & \\
\hline
\end{tabular}

5c. FET Values for Treponemal Disease (below)

\begin{tabular}{lllll}
\hline & GUAM & ROTA & TINIAN & SAIPAN \\
\hline Guam & & & \\
Rota & 0.2152 & 0.6347 & 1.000 & \\
Tinian & 1.000 & 0.4246 & & \\
Saipan & 0.7117 & & \\
\hline
\end{tabular}

5d. FET Values for Dental Caries (above) and Betel Staining (below)

\begin{tabular}{|c|c|c|c|c|}
\hline & GUAM & ROTA & TINIAN & SAIPAN \\
\hline Guam & & $<0.0001 *$ & $0.0003 *$ & $0.0038 *$ \\
\hline Rota & 0.0714 & & $<0.0001 *$ & $0.0028 *$ \\
\hline Tinian & $0.0052 *$ & 0.4841 & 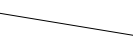 & $<0.0001 *$ \\
\hline Saipan & $0.0002 *$ & 0.2117 & 0.6331 & \\
\hline
\end{tabular}

5e. FET Values for Dental Calculus (above) and AMTL (below)

\begin{tabular}{|c|c|c|c|c|}
\hline & GUAM & ROTA & TINIAN & SAIPAN \\
\hline Guam & & $<0.0001 *$ & 0.8384 & 0.4446 \\
\hline Rota & 0.5450 & & $<0.0001^{*}$ & $<0.0001 *$ \\
\hline Tinian & $0.0014 *$ & $0.0012 *$ & 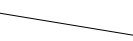 & 0.4368 \\
\hline Saipan & 1.000 & 0.5811 & $0.0036^{*}$ & \\
\hline
\end{tabular}

5f. FET Values for Dental Attrition (above) and Alveolar Defects (below)

\begin{tabular}{|c|c|c|c|c|}
\hline & GUAM & ROTA & TINIAN & SAIPAN \\
\hline Guam & & 0.2158 & 0.8715 & $<0.0001 *$ \\
\hline Rota & $0.0245 *$ & & 0.2506 & $0.0003 *$ \\
\hline Tinian & 0.1536 & $0.0059 *$ & 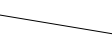 & $<0.0001^{*}$ \\
\hline Saipan & $0.0103 *$ & 1.000 & $0.0047^{*}$ & \\
\hline
\end{tabular}

* indicates statistically significant values. 


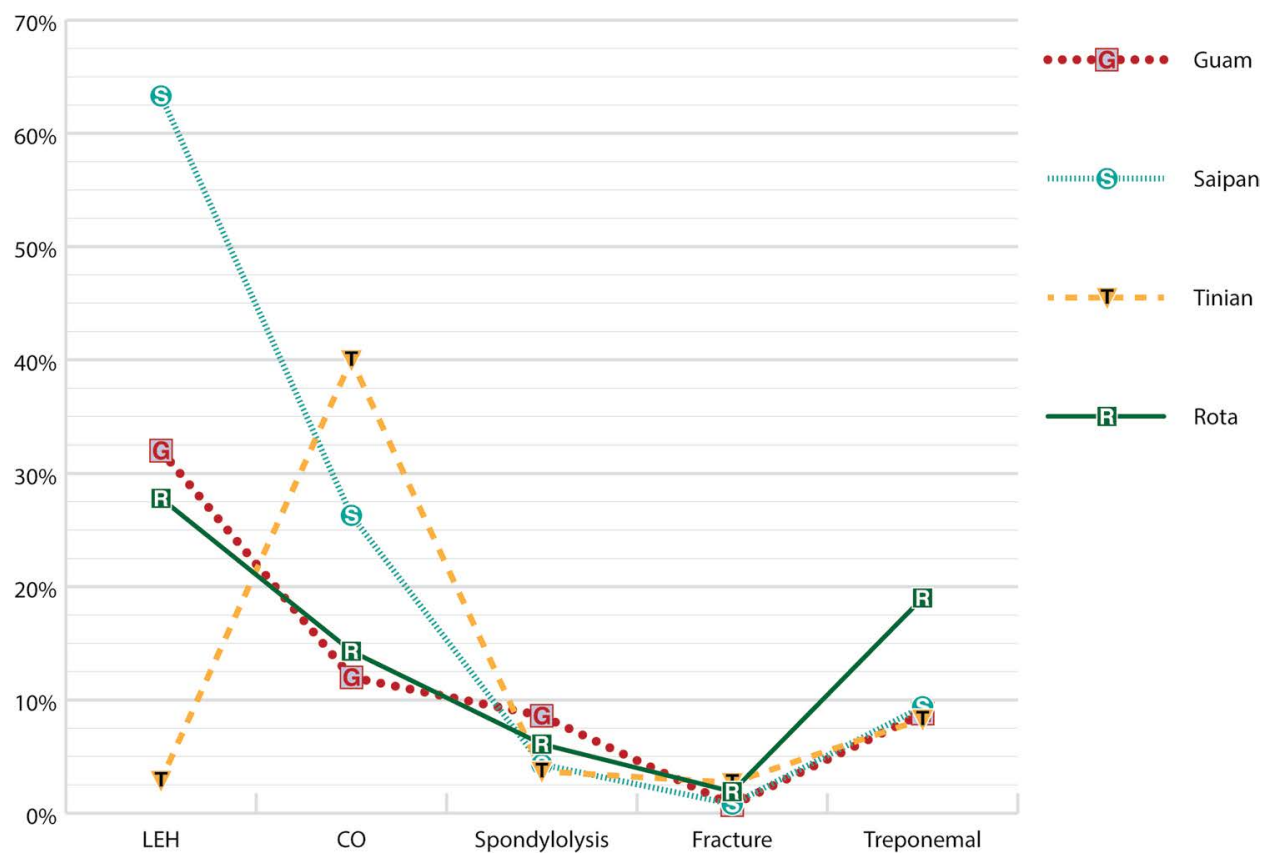

Fig. 4. Frequency of occurrence of linear enamel hypoplasia (LEH), cribra orbitalia (CO), spondylolysis, limb bone fracture, and treponemal infection in male skeletons from Guam, Saipan, Tinian, and Rota.

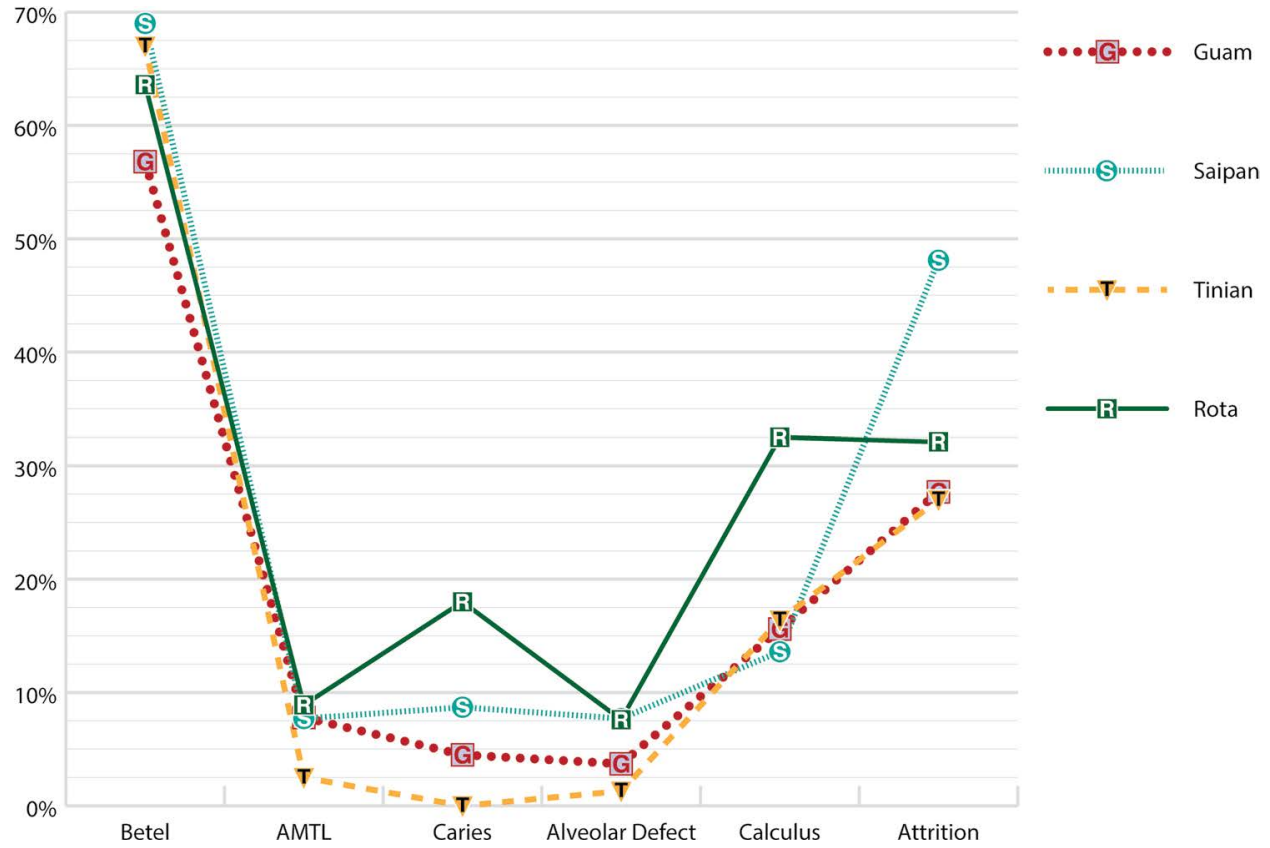

Fig. 5. Frequency of occurrence of betel-stained teeth, antemortem tooth loss (AMTL), dental caries, alveolar defect, dental calculus, and dental attrition in male skeletons from Guam, Saipan, Tinian, and Rota. 
Table 6. Female Stature (cm) for the Skeletons from the Mariana Islands (6a); Two-Tailed $p$ Values Obtained from Unpaired t-Tests Comparing Stature BETWEEN ISLANDS (6b)

$6 a$.

\begin{tabular}{lrccc}
\hline ISLAND & N & MEAN & MINIMUM & MAXIMUM \\
\hline Guam & 8 & 162.4 & 156.7 & 168.4 \\
Rota & 17 & 160.5 & 155.8 & 170.6 \\
Tinian & 9 & 159.8 & 155.5 & 166.7 \\
Saipan & 11 & 160.0 & 154.9 & 164.6 \\
\cline { 2 - 5 } Total & 45 & 160.6 & 154.9 & 170.6 \\
\hline
\end{tabular}

Note: Stature estimates were made using Houghton et al. (1975) formulae.

$6 \mathrm{~b}$.

\begin{tabular}{lcccc}
\hline & GUAM & ROTA & TINIAN & SAIPAN \\
\hline Guam & - & 0.2862 & 0.1739 & 0.1614 \\
Rota & & - & 0.6703 & 0.7305 \\
Tinian & & & - & 0.9060 \\
Saipan & & & & - \\
\hline
\end{tabular}

Note: All $p$ values are considered not to be statistically significant (95\% confidence interval).

No significant differences for the frequencies of LEH, limb bone fractures, and spondylolysis were observed for females between islands (Table 7, Fig. 6). With the exception of Tinian (30\%) and Guam (0\%), no significant differences in female frequencies of $\mathrm{CO}$ were observed between islands. Likewise with the exception of Guam (4.1\%) and Rota (26.9\%), no significant differences in female frequencies of treponemal infection were observed between islands. The greatest similarity of these indicators was observed between Guam and Rota, followed by Tinian and Saipan. Overall, there are few differences in female health between the islands. The overall frequencies of $\mathrm{CO}$, fractures, spondylolysis, and infection are low in females. The average frequency of LEH (28.1\%) in females is moderately high compared to the other indicators.

\section{Are There Differences in Female Health between Islands?: Dental Indicators}

Comparisons between islands demonstrate that there are as many significant as there are non-significant differences in the frequencies of betel staining and dental pathology amongst females (Fig. 7, Table 7). The greatest number of significant differences for females occurs between Guam and Saipan and between Rota and Tinian, similar to the trend observed in males, but also between Guam and Tinian. No significant differences for the frequencies of alveolar defects were found between the islands and the only significant differences in the frequency of dental caries were between Tinian and Saipan and between Guam and Tinian. Again, as was the case for interisland comparisons of male health, the greatest similarity among females was observed between Guam and Rota, followed by Tinian and Saipan. 
Table 7. Fisher's Exact Test (FET) Values for Interisland Comparisons of Female Health Indicators

7a. FET Values for CO (above) and LEH (below)

\begin{tabular}{|c|c|c|c|c|}
\hline & GUAM & ROTA & TINIAN & SAIPAN \\
\hline Guam & & 1.000 & $0.0410 *$ & 0.4873 \\
\hline Rota & 0.8743 & & 0.0902 & 0.5195 \\
\hline Tinian & 0.8206 & 0.6378 & 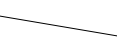 & 0.3064 \\
\hline Saipan & 0.1990 & 0.2666 & 0.1829 & \\
\hline
\end{tabular}

7b. FET Values for Limb Bone Fracture (above) and Spondylolysis (below)

\begin{tabular}{|c|c|c|c|c|}
\hline & GUAM & ROTA & TINIAN & SAIPAN \\
\hline Guam & & 1.000 & 0.5616 & 1.000 \\
\hline Rota & 1.000 & & 1.000 & 1.000 \\
\hline Tinian & 1.000 & 1.000 & & 0.4612 \\
\hline Saipan & 1.000 & 1.000 & 1.000 & \\
\hline
\end{tabular}

7c. FET Values for Treponemal Disease

\begin{tabular}{|c|c|c|c|c|}
\hline & GUAM & ROTA & TINIAN & SAIPAN \\
\hline \multicolumn{5}{|l|}{ Guam } \\
\hline Rota & $0.0027 *$ & & & \\
\hline Tinian & 0.4317 & 0.3903 & & \\
\hline Saipan & 0.2873 & 0.2621 & 1.000 & \\
\hline
\end{tabular}

7d. FET Values for Dental Caries (above) and Betel Staining (below)

\begin{tabular}{lcccc}
\hline & GUAM & ROTA & TINIAN & SAIPAN \\
\hline Guam & & 0.1504 & $0.0007^{*}$ & 0.8476 \\
Rota & 0.2279 & $<0.0001^{*}$ & 0.0606 & 0.2304 \\
Tinian & $<0.0001^{*}$ & $<0.0001^{*}$ & $<0.0001^{*}$ & $0.0027^{*}$ \\
Saipan & $<0.0001^{*}$ & & \\
\hline
\end{tabular}

7e. FET Values for Dental Calculus (above) and AMTL (below)

\begin{tabular}{|c|c|c|c|c|}
\hline & GUAM & ROTA & TINIAN & SAIPAN \\
\hline Guam & & $0.0008^{*}$ & 0.0787 & $0.0020 *$ \\
\hline Rota & 0.4513 & & $0.0004 *$ & $0.0001^{*}$ \\
\hline Tinian & $0.0001 *$ & $0.0032 *$ & re & 0.5378 \\
\hline Saipan & $0.0142 *$ & 0.1664 & 0.0624 & \\
\hline
\end{tabular}

7f. FET Values for Dental Attrition (above) and Alveolar Defects (below)

\begin{tabular}{llcrr}
\hline & GUAM & ROTA & TINIAN & SAIPAN \\
\hline Guam & & 0.8801 & $<0.0001^{*}$ & $<0.0001^{*}$ \\
Rota & 0.7739 & 0.6301 & $<0.0001^{*}$ & $<0.0001^{*}$ \\
Tinian & 0.4796 & 0.5598 & 0.4210 & $0.0006^{*}$ \\
Saipan & 0.5047 & & \\
\hline
\end{tabular}

* indicates statistically significant values. 


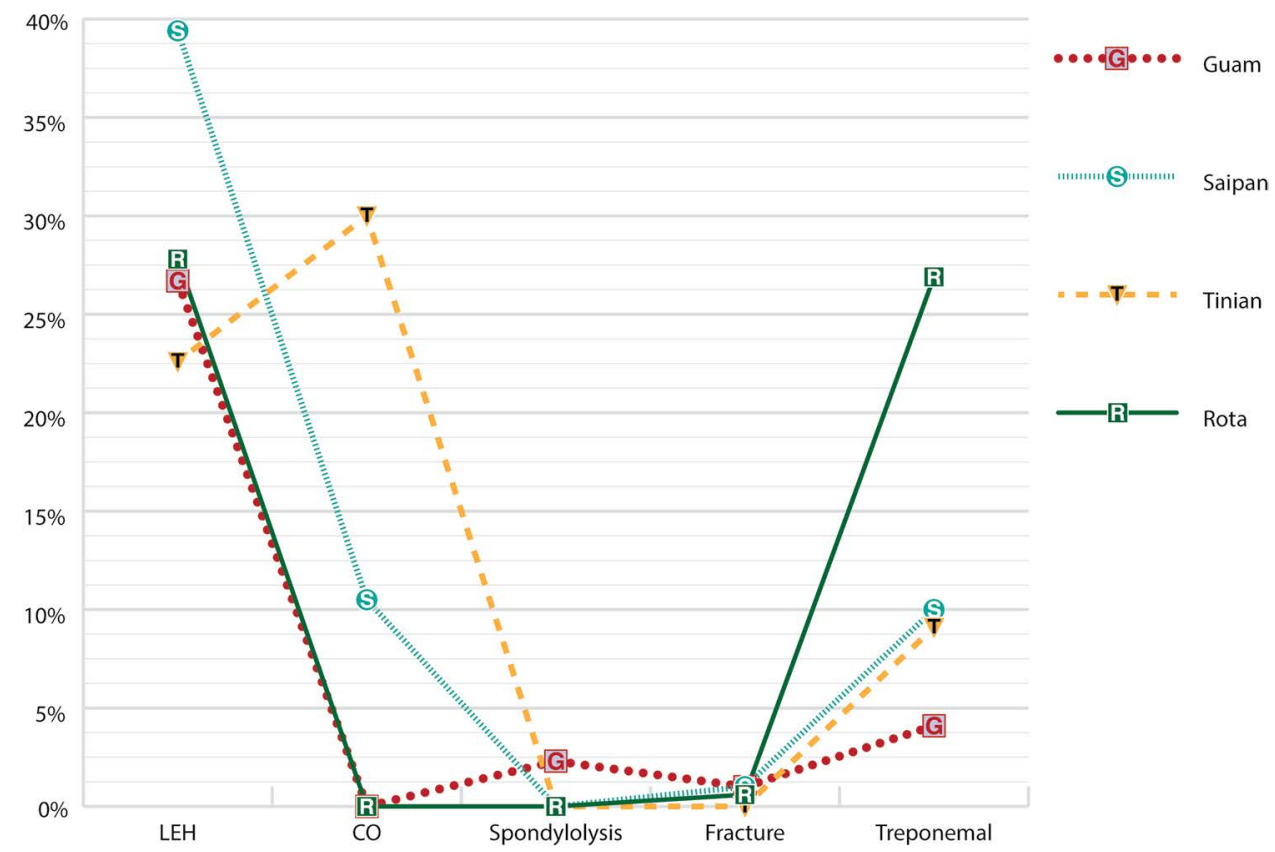

Fig. 6. Frequency of occurrence of linear enamel hypoplasia (LEH), cribra orbitalia (CO), spondylolysis, limb bone fracture, and treponemal infection in female skeletons from Guam, Saipan, Tinian, and Rota.

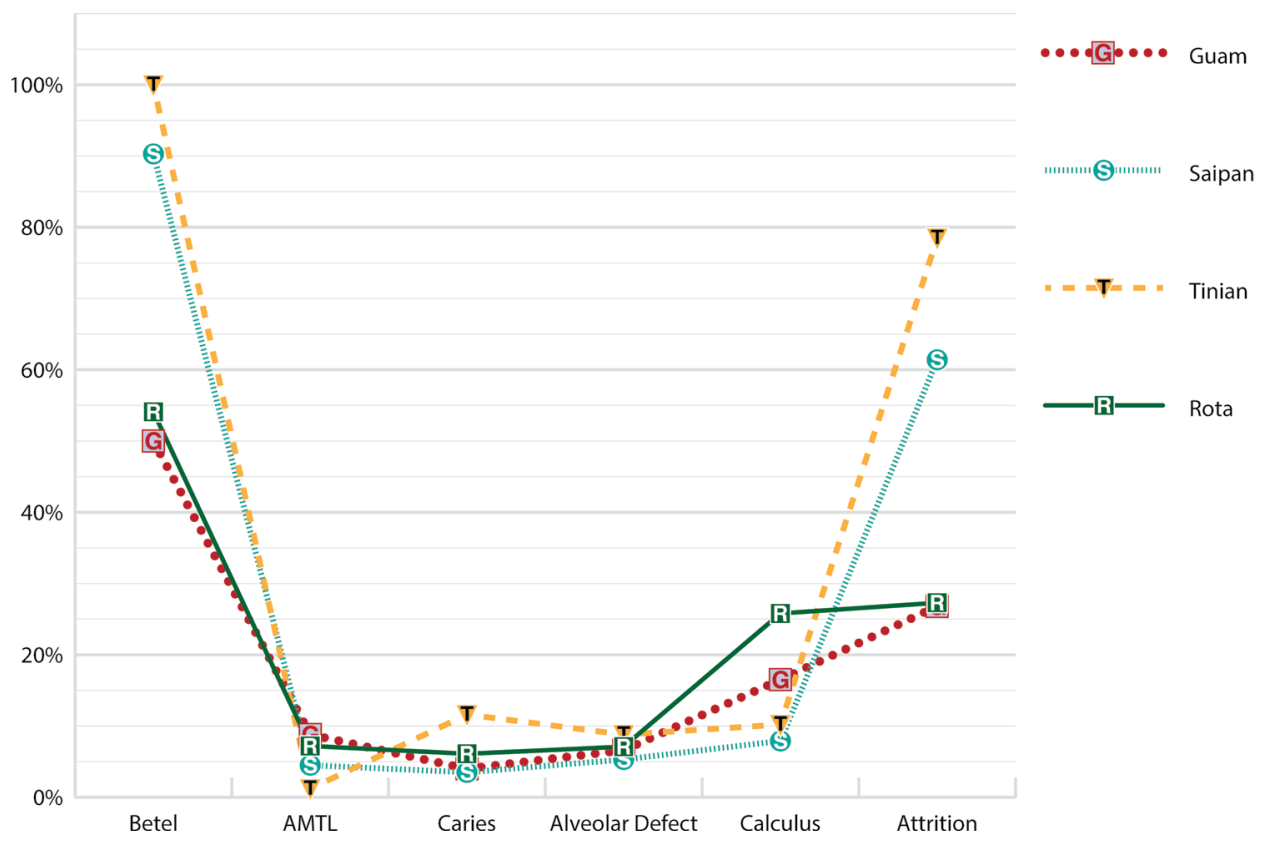

Fig. 7. Frequency of occurrence of betel-stained teeth, antemortem tooth loss (AMTL), dental caries, alveolar defect, dental calculus, and dental attrition in female skeletons from Guam, Saipan, Tinian, and Rota. 


\section{DISCUSSION}

Because the skeletal series from the Mariana Islands examined in this article are primarily from the Latte period, our discussion is restricted to this period. With the possible exception of the Naton Beach site on Guam (Walth 2013), there are very few Pre-Latte skeletons available for study. The generally poor preservation of Pre-Latte skeletons has been a further challenge to studies of Guam's earliest inhabitants.

\section{Sex Differences}

Very few differences between male and female frequencies of LEH, CO, bone fractures, spondylolysis, and infection were observed in the skeletons from the Mariana Islands. Only one non-specific stress indicator, LEH, an indicator related to early childhood health, was found to be significantly greater in Tinian females and Saipan males. Both these islands are vulnerable to water shortages, which, along with other environmental factors, may influence the risks of parasitic and other infections, especially during the weaning period. Differences in the frequency of enamel defects in females and males have often been linked to male vulnerability, since females are better buffered biologically than males (Stini 1985). However, a review by GuatelliSteinberg and Lukacs (1999) of sex differences in enamel hypoplasia in human and non-human primates concluded that sex-biased parental investment following birth influences sex differences in enamel hypoplasia more than greater male vulnerability. This raises the possibility that higher frequencies of LEH may be related to preferential investment in sons on Tinian and in daughters on Saipan. Differences between sexes for the other markers were about the same across all islands.

While not statistically significant, males had higher levels of $\mathrm{CO}$, limb bone fractures, and spondylolysis, while females had more treponemal infection. However, when island frequencies are combined, males had significantly higher frequencies of $\mathrm{CO}$ and spondylolysis than females. Given physiological differences in hormone levels and immune function in males and females, Stuart-Macadam (1998) noted that iron deficiency anemia is more common and more severe in boys than girls. The greater risk of stress fractures in the lower lumbar region among males is linked to the construction of latte sets (Arriaza 1997). Likewise, the presence of occipital superstructures in the crania of ancient Chamorro males is attributed to increased musculoskeletal exertion and strength required for heavy lifting associated with the construction of latte house foundations (Heathcote et al. 2012).

\section{Influence of Chewing Betel Nut}

Some of the observed differences in the frequencies of dental caries, AMTL, and attrition are likely influenced by the chewing of betel nut (areca seed). Epidemiological evidence demonstrates a link between chewing areca seed, increased dental attrition (IARC 2004; Kumar et al. 2004), and protection against dental caries, as well as effects on other oral-dental pathologies in living people (Chatrchaiwiwatana 2006; Howden 1984; Möller et al. 2009; Schamschula et al. 1977; Trivedy et al. 2002). Further research demonstrated that dental calculus might be greater in areca chewers (Chatrchaiwiwatana 2006). It is therefore expected that skeletons with higher levels of betel-stained teeth should exhibit lower frequencies of dental caries and higher fre- 
quencies of dental attrition and dental calculus. Likewise, a lower caries rate should also result in lower frequencies of alveolar defects and AMTL.

When the island frequencies of dental indicators are combined, females are found to have significantly more betel-stained teeth than males. While not significant, as expected, the frequency of AMTL and caries were lower and the frequency of advanced dental attrition was higher in females than in males. However, a lower frequency of alveolar defects and higher frequency of dental calculus in females were not observed in these results.

\section{Water}

One factor that may have had implications for health among the prehistoric inhabitants of the Mariana Islands is the source of drinking water. Larger, prehistoric settlements on Tinian and Saipan most likely relied on brackish well water (HunterAnderson and Butler 1995 :3). The degree of pollution from seawater and human and animal wastes on these sources of drinking water is unknown, but any contamination likely impacted health negatively. In contrast to Tinian and Saipan, Rota probably had the best sources of water overall with the existence of many water caves. Guam, with the presence of flowing rivers, water caves, and a larger landmass for water catchment, is also likely to have had comparatively good sources of drinking water. The similarities in health between Guam and Rota on the one hand and Tinian and Saipan on the other may be linked to availability of fresh drinking water on these islands.

\section{Island Size and Geography (Guam and Rota versus Tinian and Saipan)}

Two previous investigations of health and lifestyle in the Mariana Islands indicated that the prehistoric inhabitants living on the smaller islands of this archipelago experienced more stress than those living on the larger islands (Pietrusewsky et al. 1997; Pietrusewsky et al. 2014). Cultural behaviors such as chewing areca seed (betel nut) and environmental factors were cited as possible explanations for these differences. An exception to this observation is the similarity in health markers for Rota, the smallest island, and Guam, the largest island. For many of the indicators examined (i.e., stature, limb bone fracture, spondylolysis, treponemal infection, and alveolar defect) no significant differences were observed among islands.

In the present study, significant differences in male health were observed between islands for several indicators, including LEH and all the dental pathologies. For females, significant differences between islands were observed for $\mathrm{CO}$, treponemal infection, and most of the dental pathologies. Combining the male and female results, the greatest number of significant differences occurs between Guam and Saipan, Guam and Tinian, and Rota and Tinian. The greatest number of similarities is between Guam and Rota and between the more distant islands of Tinian and Saipan.

The proximity of Guam to Rota in the south and Tinian to Saipan in the north may have occasioned more frequent contact between the inhabitants of these island pairs for marriage partners, trade, exchange, and access to resources. These interactions may have had an impact on health. The proximity of the smaller islands (Rota and Tinian) to the two largest islands (Guam and Saipan) would have made 
permanent settlement on the smaller islands more desirable (Hunter-Anderson and Butler 1995 :35).

Hunter-Anderson (2010) further asserts that a possible cultural adaptation to environmental fluctuations experienced by the prehistoric Chamorro may have been maintenance of social and/or genetic networks with people living in neighboring locales as well as nearby and more distant islands. During times of severe climatic fluctuations, such as during the LIA, these larger interisland lineage or social networks may have contracted, leading to large island/small island partnerships that would have helped minimize the health vulnerabilities of those living on the smaller islands. The identification in the archaeological record of two distinct ceramic traditions, one for Guam and Rota and another for Saipan and Tinian (Dickinson et al. 2001; Graves et al. 1990), supports this geographic and possibly genetic patterning, and may explain at least in part the observed differences in health between these islands.

\section{CONCLUSIONS}

This study, based on 333 skeletons from the Mariana Islands, mostly from the Latte period (A.D. 900-1700), found very few differences between sexes for each of the four main islands for the risk of anemia, infection, or injury. With the exception of LEH, a childhood indicator of health, the observed patterns of differences between sexes are consistent across the islands: males generally having higher frequencies of $\mathrm{CO}$, fractures, and spondylolysis, while females generally have more infection. When frequencies for the islands are combined, males were found to have significantly more CO and spondylolysis than females. However, with the exception of AMTL and dental calculus, significant differences in the frequencies of dental pathology and betel-stained teeth were observed between sexes, with Tinian Island showing the greatest number of differences. The frequencies of AMTL, caries, and dental calculus were generally higher in males. For females, frequencies of betel-stained teeth, alveolar defects, and attrition were generally higher. Chewing areca seed (betel nut) is cited as likely influencing these dental pathology frequencies.

Examining male health across the islands demonstrates no significant differences for stature, anemia, trauma, or infection, but significant differences for betel and dental pathology were observed. Likewise, there are few differences between islands in female stature, trauma, and infection, but, with the exception of alveolar defects, differences in dental pathology between islands were observed.

The prehistoric inhabitants of Guam and Rota have similar health profiles, as do those on Tinian and Saipan. Overall, with the exception of treponemal infection, which was likely already endemic during the Latte period, the early inhabitants of the Mariana Islands enjoyed overall good health. Their relatively tall stature, low frequencies of fractures and anemia, and generally good dental health support this conclusion. Included among the factors that are likely to have influenced the health of these prehistoric people were access to fresh drinking water, island size, microclimates, differential access to resources, vulnerability to natural disasters, climate change, social and lineal networks, and cultural practices.

Additional well-dated skeletons from the Mariana Islands from the earliest settlement to the Latte and historic periods will allow verification of these conclusions as well as examination of possible temporal changes in health. Future research, including DNA analysis and isotope analysis, will help refine whether some of the observed dif- 
ferences between islands may be due to a shared genetic predisposition of those living on proximate islands and whether they have a shared susceptibility or resistance to disease that result in similar health outcomes.

\section{ACKNOWLEDGMENTS}

Our thanks to Mr. Marween Yagan, Graphics Specialist, Center for Instructional Support, University of Hawai'i at Mānoa, who produced the figures. Vincent Sava kindly allowed us to use some of his data recorded on skeletons excavated during waterline construction in Songsong Village in 1997 by Paul H. Rosendahl, Ph.D., Inc. We gratefully acknowledge the support of the International Archaeological Research Institute, Inc. (Honolulu) and the Historic Preservation Division of the Commonwealth of the Northern Mariana Islands for access to several important skeletal series used in this study. Swift and Harper Archaeological Resource Consulting, Saipan, received U.S. Capital Improvement funds for the Tinian Waterline Project and U.S. Federal Highway funds for the Tinian Route 202 Project. Finally, we are grateful for the helpful comments and suggestions of two anonymous reviewers and the editors.

\section{REFERENCES CITED}

Alkire, William H.

1977 An Introduction to the Peoples and Cultures of Micronesia, 2nd ed. Menlo Park, CA: Cummings Publishing Co.

Arriaza, Bernardo T.

1997 Spondylolysis in prehistoric human remains from Guam and its possible etiology. American Journal of Physical Anthropology 104 : 393-397.

Athens, J. Stephen, Michael F. Dega, and Jerome V. Ward

2004 Austronesian colonization of the Mariana Islands: The paleoenvironmental evidence. Bulletin of the Indo-Pacific Prehistory Association 24:21-30.

Athens, J. Stephen, and Jerome V. Ward

2004 Holocene vegetation, savanna origins and human settlement of Guam. Records of the Australian Museum, supplement no. 29:15-30.

Baker, Brenda, and George J. Armelagos

1988 The origin and antiquity of syphilis; paleopathological diagnosis and interpretation. Current Anthropology 29:703-737.

BATH, JOYCE

1986 The San Vitores Road Project, part 1: Final Report. Prepared for Maeda Pacific Corporation and Maeda Road Construction Co., Ltd.

Brothwell, Don R.

1981 Digging Up Bones, 3rd ed. Ithaca, NY: Cornell University Press.

Buikstra, Jane E., and Douglas H. Ubelaker

1994 Standards for Data Collection from Human Skeletal Remains. Arkansas Archaeological Survey Research Series No. 44. Fayetteville: Arkansas Archaeological Survey.

BUtLER, Brian M.

1988 Archaeological Investigations of the North Coast of Rota, Mariana Islands. Micronesian Archaeological Survey Report No. 23. Center for Archaeological Investigations Occasional Paper No. 8. Carbondale: Southern Illinois University.

1990 Pots as tools: The Marianas case. Micronesica, supplement no. 2:33-46.

Carruth, Robert L.

2003 Ground-water Resources of Saipan, Commonwealth of the Northern Mariana Islands. Water Resources Investigation Report 03-4178. Honolulu: United States Geological Survey.

Carson, Mike T.

2012a Evolution of an Austronesian landscape: The Ritidian site in Guam. Journal of Austronesian Studies 3(1) : 55-86. 
$2012 b$ An overview of Latte period archaeology. Micronesica 42(1-2): 1-79.

2014 First Settlement of Remote Oceania: Earliest Sites in the Mariana Islands. New York: Springer.

Chatrchaiwiwatana, S.

2006 Dental caries and periodontitis associated with betel quid chewing: Analysis of two data sets. Journal of the Medical Association of Thailand 89:1004-1011.

Cohen, Mark Nathan, and George J. Armelagos, eds.

1984 Paleopathology at the Origins of Agriculture. New York: Academic Press.

Craib, John L.

1992 Data Recovery Project SNM Hotel Area, Rota: End of Field Report. Report submitted to SNM Corporation, Rota and Commonwealth of the Northern Mariana Islands Historical Preservation Office, Saipan.

Davis, Bertell D., Myra J. Tomonari-Tuggle, and Stephen Wickler

1992 Archaeological Investigations at the Leo Palace Hotel Site, Naton Beach, Tumon Bay, Guam, vol. I: Archaeological Data Recovery, Burial Recovery, and Monitoring. Report prepared for Sumitomo Construction Company, Tamuning, Guam. Honolulu: International Archaeological Research Institute, Inc.

Dickinson, William R., Brian M. Butler, Darlene R. Moore, and Marilyn K. Swift

2001 Geological sources and geographic distribution of sand tempers in prehistoric potsherds from the Mariana Islands. Geoarchaeology: An International Journal 16(8): 827-854.

Dixon, Boyd J., and Richard Schaefer

2014 Archaeological investigation of caves and rock shelters on Guam and Tinian: A synthesis of their use through time. Journal of Pacific Archaeology 5(1):52-74.

Dixon, Boyd J., David J. Welch, and Coral M. Magnuson

2003 Archaeological Data Recovery of Site TN-1-691, West Tinian Airport Improvement Area, Island of Tinian. Prepared for Commonwealth Ports Authority, Saipan, MP, CNMI. Honolulu: International Archaeological Research Institute, Inc.

Douglas, Michele Toomay, and Rona M. Ikehara

1992 Archaeological Investigations at the Leo Palace Hotel Site, Naton Beach, Tumon Bay, vol. II: Osteological Study of Prehistoric Chamorro Skeletal Remains. Report submitted to Sumitomo Construction Company, Tamuning, Guam. Honolulu: International Archaeological Research Institute, Inc.

Douglas, Michele Toomay, Michael Pietrusewsky, and Rona M. Ikehara-Quebral

1997 Skeletal biology of Apurguan: A precontact Chamorro site on Guam. American Journal of Physical Anthropology 104:291-314.

Farrell, Don

1991 History of the Northern Mariana Islands. Commonwealth of the Northern Mariana Islands Public School System.

Fitzpatrick, Scott M., and Richard Callaghan

2013 Estimating trajectories of colonization to the Mariana Islands, Western Pacific. Antiquity $87: 840-853$.

FOSBERG, F. RAYMOND

1960 The vegetation of Micronesia, part 1: General descriptions, the vegetation of the Mariana Islands, and a detailed consideration of the vegetation of Guam. Bulletin of the American Museum of Natural History 119:1-75.

Goodman, Alan H., Debra L. Martin, and George J. Armelagos

1984 Indications of stress from bones and teeth, in Paleopathology at the Origins of Agriculture: 13-49, ed. Mark N. Cohen and George J. Armelagos. Orlando: Academic Press.

Goodman, Alan H, and Jerome C. Rose

1990 Assessment of systemic physiological perturbations from dental enamel hypoplasias and associated histological structures. Yearbook of Physical Anthropology 33:59-110.

1991 Dental enamel hypoplasias as indicators of nutritional status, in Advances in Dental Anthropology: 279-294, ed. Mark A. Kelley and Clark Spencer Larsen. New York: Wiley-Liss.

Graves, Michael W.

1986 Organization and differentiation within late prehistoric ranked social units, Mariana Islands. Journal of Field Archaeology 13(2) :139-154. 
Graves, Michael W., Terry L. Hunt, and Darlene Moore

1990 Ceramic production in the Mariana Islands: Explaining change and diversity in prehistoric interaction and exchange. Asian Perspectives 29(2):211-233.

Guatelli-Steinberg, Debbie, and John R. Lukacs

1999 Interpreting sex differences in enamel hypoplasia in human and non-human primates: Developmental, environmental, and cultural considerations. Yearbook of Physical Anthropology 42:73126.

Hanson, Douglas B.

1988 Prehistoric mortuary practices and human biology, in Archaeological Investigations of the North Coast of Rota, Mariana Islands: Micronesian Archaeological Survey Report No. 23:375-435, ed. Brian M. Butler. Center for Archaeological Investigations Occasional Paper No. 8. Carbondale: Southern Illinois University.

Hanson, Douglas B., and Brian M. Butler

1997 A biocultural perspective on Marianas prehistory: Recent trends in bioarchaeological research. American Journal of Physical Anthropology 104:271-290.

Hasebe, Kotondo

1938 The natives of the South Sea Archipelago. Jinruigaku Senshigaku Koza [Lectures on anthropology and prehistory] 1:1-35 (in Japanese).

Heathcote, Gary M., Vincent P. Diego, Hajime Ishida, and Vincent J. Sava

2012 Legendary Chamorro strength: Skeletal embodiment and the boundaries of interpretation, in The Bioarchaeology of Individuals: 44-67, ed. Ann L. W. Stodder and Ann M. Palkovich. Gainesville: University Press of Florida.

Hillson, Simon W.

1996 Dental Anthropology. Cambridge: Cambridge University Press.

2008 Dental pathology, in Biological Anthropology of the Human Skeleton: 301-340, ed. M. Anne Katzenberg and Shelley R. Saunders. New York: Wiley-Liss.

Houghton, Philip, B. Foss Leach, and Douglas G. Sutton.

1975 The estimation of stature of prehistoric Polynesians in New Zealand. Journal of the Polynesian Society $84: 325-336$.

Howden, G. F.

1984 The cariostatic effect of betel nut chewing. Papua New Guinea Medical Journal 27(3-4) : 123131.

Hung, Hsiao-chun, Mike T. Carson, Peter Bellwood, Fredeliza Z. Campos, Philip J. Piper, Eusebio Dizon, Mary Jane Louise A. Bolunia, Marc Oxenham, and Zhang Chi

2011 The first settlement of Remote Oceania: The Philippines to the Marianas. Antiquity 85: 909-926.

Hunter-Anderson, Rosalind L.

2010 Cultural responses to a late Holocene climatic oscillation in the Mariana Islands, Micronesia: Lessons from the past. Human Ecology Review 17(2) : 148-159.

2012 Running to stay in place: An adaptive escalation model for the Latte period. Micronesica 42(1-2): 148-182.

Hunter-Anderson, Rosalind L., And Brian M. Butler

1995 An Overview of Northern Marianas Prehistory. Micronesian Archaeology Survey Report No. 31. Saipan: The Micronesian Archaeological Survey, Division of Historic Preservation, Department of Community and Cultural Affairs.

iARC (International Agency for Research on Cancer)

2004 Betel-quid and Areca-nut Chewing and Some Areca-nut-derived Nitrosamines. IARC Monographs on the Evaluation of Carcinogenic Risks to Humans, vol. 85. Lyon: World Health Organization.

Ikehara-Quebral, Rona M., And Michele Toomay Douglas

2006 Osteological analysis of human skeletal and dental remains, in In Back of the Cathedral: Archaeological Investigations in the Heart of Hagåña Guam. Archaeological Inventory Survey, Data Recovery, Burial Recovery, and Monitoring at the Academy of Our Lady of Guam Gymnasium Site, vol. 1: Narrative: 185-195, ed. David J. Welch and Judith R. McNeill. Draft report prepared for the Archdiocese of Guam. Honolulu: International Archaeological Research Institute, Inc. 
Keel, Thomas M., John E. Mylroie, and John W. Jensen

2005 The Caves and Karst of Rota Island, Commonwealth of the Northern Mariana Islands. Technical Report No. 107. Mangilao: Water and Environment Research Institute of the Western Pacific, University of Guam.

Kumar, S., G. Pamar, and H. N. Saiyed

2004 Nut and tobacco chewing. British Dental Journal 197:292.

Larsen, Clark Spencer

2015 Bioarchaeology: Interpreting Behavior from the Human Skeleton, 2nd ed. Cambridge: Cambridge University Press.

LÉvesque, RODRIGUE

1997 Translation of Berman Jesuit Documents. Prepared for the Commonwealth Council for the Humanities. Saipan: Historic Preservation Office, Commonwealth of the Northern Marianas.

Lieverse, ANgela R.

1999 Diet and the aetiology of dental calculus. International Journal Osteoarchaeology 9:219-232.

Lieverse, Angela R., David W. Link, Vladimir Ivanovich Bazaliiskly, Olga Ivanovna Goriunova, AND ANDZREJ W. WeBer

2007 Dental health indicators of hunter-gatherer adaptation and cultural change in Siberia's CisBaikal. American Journal of Physical Anthropology 134:323-339.

Lovell, Nancy C.

2008 Analysis and interpretation of skeletal trauma, in Biological Anthropology of the Human Skeleton: 341-386, ed. M. Anne Katzenberg, and Shelly R. Saunders. New York: Wiley-Liss.

LuKacs, JoHN R.

2007 Dental trauma and antemortem tooth loss in prehistoric Canary Islanders: Prevalence and contributing factors. International Journal of Osteoarchaeology 17(2):157-173.

Lukacs, John R., ANd Leah L. Largaespada

2006 Explaining sex differences in dental caries prevalence: Saliva, hormones and "life-history" etiologies. American Journal of Human Biology 18:540-555.

Mays, Simon

2010 The Archaeology of Human Bones, 2nd ed. New York: Routledge.

McManamon, Francis P., ED.

1990 The Archaeology of Songsong Village, Rota, Northern Mariana Islands. Saipan: Historic Preservation Office, Commonwealth of the Northern Marianas. http://core.tdar.org/document/4290/ the-archeology-of-songsong-village-rota-northern-mariana-islands

Merbs, Charles F.

1996 Spondylolysis and spondylolisthesis: A cost of being an erect biped or a clever adaptation? Yearbook of Physical Anthropology $101: 201-228$.

MÖller, I. J., J. J. DBorg, AND I. EFFENDi

2009 The relation between betel chewing and dental caries. European Journal of Oral Sciences $85: 64-70$.

MOORE, DARLENE R.

1990 Description and analysis of Songsong pottery, in The Archaeology of Songsong Village, Rota, Northern Mariana Islands: 161-206, ed. Francis P. McManamon. Saipan: Historic Preservation Office, Commonwealth of the Northern Marianas. http://core.tdar.org/document/4290/thearcheology-of-songsong-village-rota-northern-mariana-islands

Nunn, Patrick D.

2007 Climate, Environment and Society in the Pacific during the Last Millennium. New York: Elsevier.

OrTner, Donald J.

1998 Male-female immune reactivity and its implications for interpreting evidence in human skeletal paleopathology, in Sex and Gender in Paleopathological Perspective: 79-92, ed. Anne L. Grauer and Patricia Stuart-Macadam. Cambridge: Cambridge University Press.

2003 Identification of Pathological Conditions in Human Skeletal Remains, 2nd ed. New York: Academic Press.

Oxenham, Marc Fredrick, and Ivor Cavill

2010 Porotic hyperostosis and cribra orbitalia: The erythropoietic response to iron-deficiency anemia. Anthropological Science 118(3): 199-200. 
Oxenham Marc Fredrick, Cornelia Locher, Lan Cuong Nguyen, and Kim Thuy Nguyen

2002 Identification of Areca catechu (betel nut) residues on the dentitions of Bronze Age inhabitants of Nui Nap, Northern Vietnam. Journal of Archaeological Science 29(9): 909-915.

Pietrusewsky, Michael

1986a A Study of Human Skeletal Remains from Three Sites in the Northern Mariana Islands. A Report to the Historic Preservation Office, Saipan, CNMI. Honolulu: Department of Anthropology, University of Hawai' $i$ at Mānoa.

$1986 b$ Report on the Human Skeletal and Dental Remains Excavated during the San Vitores Road Project, Tumon Bay, Guam, Mariana Islands. Prepared for Maeda Pacific Corporation and Maeda Road Construction Company, Ltd., a Joint Venture. Honolulu: Department of Anthropology, University of Hawai'i at Mānoa.

1988 Human Remains from Songsong Village, Rota, Commonwealth of the Northern Mariana Islands. Honolulu: Department of Anthropology, University of Hawai'i at Mānoa.

1994 Human Skeletal Remains from the SNM Hotel, Rota, Northern Mariana Islands. A Report for Bonhomme, Craib and Associates, Archaeological Consultants, Mudgeeraba, Queensland, Australia, 13 May. Honolulu: Department of Anthropology, University of Hawai'i at Mānoa.

2006 The Osteology of the Human Skeletal Remains from the Beach Road Sewer System Upgrade, Phase II (BRSS) Project, Saipan, Commonwealth of the Northern Mariana Islands. Final report prepared for Swift and Harper Archaeological Resource Consulting, Saipan and the Division of Historic Preservation, Saipan. Honolulu: Department of Anthropology, University of Hawai'i at Mānoa.

Pietrusewsky, Michael, and Christine Batista

1980 Human Skeletal and Dental Remains from Four Sites on Tinian and Saipan, Commonwealth of the Northern Mariana Islands. Final report to the Northern Marianas Archaeological Society, Inc. Honolulu: Department of Anthropology, University of Hawai'i at Mānoa.

Pietrusewsky, Michael, and Michele Toomay Douglas

1989 Human Remains from Oleai, Saipan, Commonwealth of the Northern Mariana Islands. Honolulu: Department of Anthropology, University of Hawai'i at Mānoa.

2001 T The Osteology of the Human Skeletal Remains from the Tinian Water Line Improvements Project, Tinian, Northern Mariana Islands, CNMI. Final report prepared for Swift and Harper Archaeological Resource Consulting, Saipan. Honolulu: Department of Anthropology, University of Hawai'i at Mānoa.

$2001 b$ The Osteology of the Human Skeletal Remains from the Chalan Monsignor Guerrero Road Improvements Project, Phase III, Saipan, Northern Mariana Islands, CNMI. Final report prepared for Swift and Harper Archaeological Resource Consulting, Saipan. Honolulu: Department of Anthropology, University of Hawai'i at Mānoa.

2002 Ban Chiang, a Prehistoric Village Site in Northeast Thailand I. The Human Skeletal Remains. Philadelphia: The University of Pennsylvania Museum of Archaeology and Anthropology.

2010 The Osteology of the Human Skeletons from the Reconstruction of Route 202 with Drainage Improvements Project, Tinian, Commonwealth of the Northern Mariana Islands. Final report prepared for Swift and Harper Archaeological Resource Consulting, Saipan. Honolulu: Department of Anthropology, University of Hawai'i at Mānoa.

Pietrusewsky, Michael, Michele Toomay Douglas, and Rona M. Ikehara-Quebral

1997 An assessment of health and disease in the prehistoric inhabitants of the Mariana Islands. American Journal of Physical Anthropology 104:315-342.

2003 Archaeological Investigations in Apotguan, Guam: Agana Beach Condominium Site, vol. 3: An Osteological Investigation and Comparison with Other Micronesian Series. Honolulu: International Archaeological Research Institute, Inc.

Pietrusewsky, Michael, Michele Toomay Douglas, Rona M. Ikehara-Quebral, and Lou Jane M. LEE

2007 The Osteology of the Human Skeletal Remains from Malesso, Guam. Report prepared for Guam MDCI Corporation. Honolulu: International Archaeological Research Institute, Inc.

Pietrusewsky, Michael, Michele Toomay Douglas, Marilyn K. Swift, Randy A. Harper, and Michael A. Fleming

2010 An assessment of health and lifestyle among pre-1521 Chamorro from Saipan, Commonwealth of Northern Mariana Islands. American Journal of Physical Anthropology S50:189.

2011 An assessment of health and lifestyle among prehistoric Chamorro from Tinian Island in the Northern Mariana Islands. American Journal of Physical Anthropology S52:238-239.

2014 Health in ancient Mariana Islanders: A bioarchaeological perspective. Journal of Island and Coastal Archaeology 9:319-340. 
Pietrusewsky, Michael, and Rona Ikehara-Quebral

1995 Human Skeletal Remains Found during Monitoring Activities at the SNM Hotel, Rota, Northern Mariana Islands. A Report prepared for Bonhomme, Craib and Associates, Archaeological Consultants, Mudgeeraba, Queensland, Australia. Honolulu: Department of Anthropology, University of Hawai'i at Mānoa.

Rothschild, Bruce M., and Gary M. Heathcote

1993 Characterization of the skeletal manifestations of treponemal disease yaws as a population phenomenon. Clinical Infectious Diseases 17:198-203.

Russell, SCOTT

1998 Tiempon I Manmofo'na: Ancient Chamorro Culture and History of the Northern Mariana Islands. Micronesian Archaeological Survey Report No. 32. Saipan: Northern Mariana Islands Division of Historic Preservation.

Ryan, E. Melanie

2010 Chamorro Health and Illness at a Prehistoric Coastal Habitation Site in Tumon Bay, Guam. Ph.D. diss. Australian National University, Canberra.

SAVA, Vincent J.

1999 Appendix E: Osteological Analyses. An osteological study of prehistoric human skeletal remains recovered during waterline construction in Songsong Village, Rota, Commonwealth of the Northern Mariana Islands, in Archaeological Data Recovery Songsong Water System Improvement Project, Island of Rota, CMNI: E1-E51 and Appendices A-D, ed. Jack D. Henry, Alan E. Haun, Melissa A. Kirkendall, and David DeFant. Hilo, HI: Paul H. Rosendahl, Ph.D., Inc.

Schamschula, R. G., B. L. Adkins, D. E. Barmes, and G. Charlton

1977 Betel chewing and caries experience in New Guinea. Community Dentistry and Oral Epidemiology 5 : 284-286.

Steckel, Richard H., and Jerome C. Rose, eds.

2002 The Backbone of History: Health and Nutrition in the Western Hemisphere. Cambridge: Cambridge University Press.

Stewart, T. Dale, and Alexander Spoehr

1952 Evidence on the paleopathology of yaws. Bulletin of the History of Medicine 26:538-553.

Stini, William A.

1985 Growth rates and sexual dimorphism in evolutionary perspective, in The Analysis of Prehistoric Diets: 191-226, ed. Robert I. Gilbert Jr. and John H. Mielke. Orlando: Academic Press.

Stodder, Ann L. W., E. Melanie Ryan, Rosalind L. Hunter-Anderson, Michele Toomay DougLAS, AND RoNa IKEHARA-QuEBral

2016 Under the Latte: Osteobiography and social context of a burial assemblage at Tumon Bay, Guam, in The Routledge Handbook of Bioarchaeology in Southeast Asia and the Pacific Islands: 527-568, ed. Marc Oxenham and Hallie Buckley. New York: Taylor and Francis Group.

Stuart-Macadam, Patricia L.

1989 Nutritional deficiency diseases: A survey of scurvy, rickets, and iron-deficiency anemia, in Reconstruction of Life from the Skeleton: 201-222, ed. Mehmet Yaşar İşcan and Kenneth A. R. Kennedy. New York: Alan R. Liss.

1991 Porotic hyperostosis: Changing interpretations, in Human Paleopathology: Current Syntheses and Future Options: 36-39, ed. Donald J. Ortner and Arthur C. Aufderheide. Washington, DC: Smithsonian Institution Press.

1998 Iron deficiency anemia: Exploring the difference, in Sex and Gender in Paleopathological Perspective: 45-63, ed. Anne L. Grauer and Patricia Stuart-Macadam. Cambridge: Cambridge University Press.

Thomas, David Hurst

1986 Refiguring Anthropology: First Principles of Probability and Statistics. Prospect Heights, IL: Waveland Press.

Tracey, Joshua I. Jr., Seymour O. Schlanger, John T. Stark, David B. Doan, and Harold G. May

1964 General Geology of Guam. U.S. Geological Survey Professional Paper 403-A. Washington, DC: U.S. Government Printing Office.

Trembly, DiAne

1995 On the antiquity of leprosy in Western Micronesia. International Journal of Osteoarchaeology $5: 377-384$. 
1996 Treponematosis in pre-Spanish western Micronesia. International Journal of Osteoarchaeology $6: 397-402$.

Trembly, Diane, and C. E. Tucker

1999 Human Skeletal and Dental Remains from the Tumon Bay Hyatt Site. Tumon, Tamuning Municipality, Territory of Guam. Report No. 797-060199 prepared for EIE Guam Corporation. Hilo, HI: Paul H. Rosendahl, Ph.D., Inc.

Trivedy, C. R., G. Craig, and S. Warnakulasuriya

2002 The oral health consequences of chewing areca nut. Addiction Biology 7(1): 115-125.

Vilar, Miguel G., Chim W. Chan, Dana R. Santos, Daniel Lynch, Rita Spathis, Ralph M. Garruto, And J. Koji Lum

2013 The origins and genetic distinctiveness of the Chamorros of the Marianas Islands: An mtDNA perspective. American Journal of Human Biology: The Official Journal of the Human Biology Council 25(1): 116-122.

Walker, Phillip L.

1989 Cranial injuries as evidence of violence in prehistoric southern California Indians. American Journal of Physical Anthropology 80:313-323.

Walker, Phillip L., Rhonda R. Bathurst, Rebecca Richman, Thor Gjerdrum, and Valerie A. Andrushio

2009 The causes of porotic hyperostosis and cribra orbitalia: A reappraisal of the iron-deficiencyanemia hypothesis. American Journal of Physical Anthropology 139:109-125.

WALth, Cheri K., ED.

2013 Archaeological Investigations at the Naton Beach Site, Tumon Bay, Guam, vol. I: The Archaeological Monitoring, Data Recovery, Burial Recovery, and Artifact Analysis. SWCA Report No. 13-504. Draft report prepared for Guam Hotel Okura, Guam. Guam: SWCA.

Ward, Graeme, and Michael Pickering

1985 The Japanese Bone Collecting Expedition on Tinian, March 1985: Its Impact Upon Historic Resources. Manuscript prepared for the Historic Preservation Co-ordinator, Tinian, and the Historic Preservation Office, Commonwealth of the Northern Mariana Islands.

WeLCh, DAVID

1991 Historic Preservation Mitigation Plan, Academy of Our Lady of Guam Gymnasium Project. Prepared for Academy of Our Lady of Guam, Agana. Honolulu: International Archaeological Research Institute, Inc.

White, Donald J.

1997 Dental calculus: Recent insights into occurrence, formation, prevention, removal and oral health effects of supragingival and subgingival deposits. European Journal of Oral Sciences $105: 508-522$.

YOUNG, Fred J.

1989 Soil Survey of the Islands of Aguijan, Rota, Saipan, and Tinian, Commonwealth of the Northern Mariana Islands. Washington, DC: United States Department of Agriculture, Soil Conservation Service. http://soils.usda.gov/survey/online_surveys/pacific_basin/index.html

\section{ABSTRACT}

The early inhabitants of the Mariana Islands encountered numerous challenges that likely affected their health, including island size, vulnerability to natural disasters, availability of resources, and shifts in climate. Other factors that could have led to differences in health include biological sex, social status, diet, and genetic factors (e.g., host resistance). This article examines the effects of environment and biological sex on the health of the earliest inhabitants of the Mariana Islands through an analysis of indicators of health recorded in skeletons from Guam, Rota, Tinian, and Saipan. The indicators of health investigated include cribra orbitalia (CO), linear enamel hypoplasia (LEH), stature, trauma, infection, and dental disease (antemortem tooth loss [AMTL], dental caries, alveolar defect, dental calculus, and attrition). Betel staining of teeth is also examined. To determine if there are differences attributable to sex, male and female data are compared for each island separately and then for all the islands combined. To examine differences between islands, separate comparisons of these indicators are made for males and 
females. Examining islands separately, no significant sex differences were observed for $\mathrm{CO}$, spondylolysis, fractures, treponemal infection, AMTL, or dental calculus. Significant sex differences were observed for LEH, betel-stained teeth, and the other dental pathologies. With few exceptions, sex differences in the observed indicators were consistent across islands. Observing male and female health across the islands revealed no significant differences for stature, trauma or infections. For the remaining indicators, significant differences were observed. Similarities in health between Guam and Rota in the south and Tinian and Saipan located farther north suggest that geography, environmental constraints, and social and cultural networking were important variables affecting the health and lives of the early inhabitants of the Mariana Islands. Keywords: Mariana Islands, Chamorro, bioarchaeology, indicators of health, palaeopathology. 